\title{
Laboratory studies of immersion and deposition mode ice nucleation of ozone aged mineral dust particles
}

\author{
Z. A. Kanji ${ }^{1, *}$, A. Welti ${ }^{1}$, C. Chou ${ }^{1, * *}$, O. Stetzer $^{1}$, and U. Lohmann ${ }^{1}$ \\ ${ }^{1}$ Institute for Atmospheric and Climate Sciences, ETH, Zurich, 8092, Switzerland \\ * now at: Air Quality Research Division, Environment Canada, Toronto, ON, M3H 5T4, Canada \\ ** now at: Science and Technology Research Institute, University of Hertfordshire, College Lane, AL10 9AB, Hatfield, UK
}

Correspondence to: Z. A. Kanji (zamin.kanji@env.ethz.ch)

Received: 14 March 2013 - Published in Atmos. Chem. Phys. Discuss.: 2 April 2013

Revised: 2 August 2013 - Accepted: 5 August 2013 - Published: 10 September 2013

\begin{abstract}
Ice nucleation in the atmosphere is central to the understanding the microphysical properties of mixed-phase and cirrus clouds. Ambient conditions such as temperature $(T)$ and relative humidity $(\mathrm{RH})$, as well as aerosol properties such as chemical composition and mixing state play an important role in predicting ice formation in the troposphere. Previous field studies have reported the absence of sulfate and organic compounds on mineral dust ice crystal residuals sampled at mountain top stations or aircraft based measurements despite the long-range transport mineral dust is subjected to. We present laboratory studies of ice nucleation for immersion and deposition mode on ozone aged mineral dust particles for $233<T<263 \mathrm{~K}$. Heterogeneous ice nucleation of untreated kaolinite (Ka) and Arizona Test Dust (ATD) particles is compared to corresponding aged particles that are subjected to ozone concentrations of $0.4-4.3 \mathrm{ppmv}$ in a stainless steel aerosol tank. The portable ice nucleation counter (PINC) and immersion chamber combined with the Zurich ice nucleation chamber (IMCA-ZINC) are used to conduct deposition and immersion mode measurements, respectively. Ice active fractions as well as ice active surface site densities $\left(n_{\mathrm{s}}\right)$ are reported and observed to increase as a function of decreasing temperature. We present first results that demonstrate enhancement of the ice nucleation ability of aged mineral dust particles in both the deposition and immersion mode due to ageing. We also present the first results to show a suppression of heterogeneous ice nucleation activity without the condensation of a coating of (in)organic material. In immersion mode, low ozone exposed Ka particles showed enhanced ice activity requiring a median freezing temperature of $1.5 \mathrm{~K}$ warmer than that of untreated $\mathrm{Ka}$, whereas high ozone ex-
\end{abstract}

posed ATD particles showed suppressed ice nucleation requiring a median freezing temperature of $3 \mathrm{~K}$ colder than that of untreated ATD. In deposition mode, low exposure Ka had ice active fractions of an order of magnitude higher than untreated Ka, whereas high ozone exposed ATD had ice active fractions up to a factor of 4 lower than untreated ATD. From our results, we derive and present parameterizations in terms of $n_{\mathrm{S}}(T)$ that can be used in models to predict ice nuclei concentrations based on available aerosol surface area.

\section{Introduction}

Ice crystals form in tropospheric clouds through homogeneous and heterogeneous nucleation mechanisms. Understanding the processes of freezing and the conditions that lead to ice formation is necessary since ice nucleation governs the microphysical properties of ice and mixed-phase clouds whose contribution to the earth's radiation budget are still uncertain (Denman et al., 2007). Knowledge of the properties of atmospheric particles that influence ice nucleation is necessary in order to appropriately treat the process in global circulation models and predict ice crystal concentrations in the troposphere for a number of reasons. First, accurately predicting water vapour mixing ratios requires the quantification of ice particle sizes and numbers in the atmosphere since ice is an important sink of gas phase water, an especially active green-house gas in the upper troposphere (Lindzen, 1990). Second, ice acts as a surface for heterogeneous chemistry through the uptake of many trace gases (Kolb et al., 2010; Abbatt, 2003), for example, $\mathrm{SO}_{2}$ and $\mathrm{O}_{3}$, 
thus ice particles in the atmosphere play a crucial role in determining the chemical composition of the troposphere. Third, global precipitation is mostly initiated by the ice phase thus determining cloud cover and life time are dependent on the amount of ice formed in a mixed-phase cloud (Lohmann and Feichter, 2005).

Heterogeneous ice nucleation - where an atmospheric solid particle aids ice crystallization - is classified into different modes (Vali, 1985): deposition mode (in which vapour supersaturated with respect to ice deposits onto an aerosol particle surface directly as ice); contact freezing (in which freezing initiates at the interface of contact upon the collision of an interstitial particle and a supercooled droplet); and lastly immersion/condensation freezing (where a single particle fully/partially immersed in water will aid freezing of a supercooled droplet by stabilising (reducing the Gibb's Free Energy) the ice nucleation process at the surface of the immersed particle). By convention, condensation freezing is thought to take place when freezing follows water condensation on a particle at temperatures below $273 \mathrm{~K}$ (Murray et al., 2012 and references therein; Hoose and Möhler, 2012).

Heterogeneous ice nucleation on the surface of mineral dust (MD) particles has been studied extensively in previous laboratory and field studies (Hoose and Möhler, 2012; Murray et al., 2012 and references therein; Cantrell and Heymsfield, 2005). MD particles are considered to be one of the most effective heterogeneous ice nuclei (IN) amongst biological particles (Pratt et al., 2009), bacteria, pollen and diatoms (Alpert et al., 2011; Knopf et al., 2011; Möhler et al., 2007). Airborne MD has the largest emission rate and average aerosol optical depth of all aerosol types (Satheesh and Moorthy, 2005). Due to the large burden of MD up to $1500 \mathrm{Tg} \mathrm{yr}^{-1}$ (Satheesh and Moorthy, 2005; Andreae and Rosenfeld, 2008), the potency of dust storms and the long residence time of several weeks in the absence of precipitation in the troposphere (Prospero, 1999), significant amounts of MD particles undergo long-range transport and get lofted to altitudes as high as $6 \mathrm{~km}$ within the Saharan Air Layer (Colarco et al., 2003). Field studies that observed the chemical composition using single particle mass spectrometry found MD particles that have undergone long-range transport (typically from Asia or Africa to the USA) were enriched in ice crystal residuals. These particles were sampled through an IN counter that heterogeneously activated ambient particles from the upper free troposphere (DeMott et al., 2003a; Richardson et al., 2007) or as ice crystals directly in leewave-clouds (Field et al., 2012) and in convective cloud anvils (DeMott et al., 2003b; Cziczo et al., 2004). Field studies also report an enhanced ice crystal number concentration in clouds in the presence of dust storms (Sassen et al., 2003; Cziczo et al., 2004; DeMott et al., 2003b) suggesting the importance of dust to ice formation in the troposphere. Investigations of ice nucleation properties in the deposition and condensation/immersion mode for a variety of MD such as Arizona Test Dust (ATD), Asian dust, Canary Island dust, kaoli- nite (Ka), illite, Israeli dust, montmorillonite and Saharan dust as a function of temperature $(T)$, onset relative humidity (RH) and normalised to surface area of the aerosol particles have been reported (Hoose and Möhler, 2012 and references therein; Murray et al., 2012 and references therein). Laboratory based studies that focussed on ice nucleation of MD consistently show that there is a significant particle size dependency in all, deposition, immersion/condensation and contact modes (Kanji and Abbatt, 2010; Niemand et al., 2012; Lüönd et al., 2010; Welti et al., 2009, 2012; Ladino et al., 2011; Archuleta et al., 2005; Koehler et al., 2007) for defining ice nucleation onsets as a function of $T$ and/or RH. These studies consistently conclude that larger particles are more effective heterogeneous IN requiring lower RH or less supercooling for the onset of ice formation. It is also evident that ice nucleation depends on surface composition of the particle (e.g. Kanji et al., 2008). Under the broad category of MD it is difficult to quantify the most effective atmospherically relevant MD IN. Recently a study by DeMott et al. (e.g. 2010) showed that for predicted concentrations of IN to agree with observed IN concentrations, parameterizations needed to be based on the number of particles that had diameters larger than $500 \mathrm{~nm}$, suggesting that in the atmosphere there is a tendency towards larger particles acting as IN.

Ice nuclei parameterizations from previous laboratory studies that are used to extrapolate IN concentrations in the field, generally over predict IN concentrations (Eidhammer et al., 2009). Parameterizations of IN concentrations based on laboratory studies (Marcolli et al., 2007; Diehl and Wurzler, 2004; Lüönd et al., 2010), however, are based on experiments with "clean" MD and may not be representative of what is found in the atmosphere due to the long-range transport atmospheric particles undergo. It is expected that aerosol particles in the atmosphere will interact with other atmospheric species such as trace gases and (in)organic aerosols. For example, ambient air containing Asian dust was analysed for chemical composition using single particle mass spectrometry revealed that the MD can be internally mixed with sulfate and chloride (Sullivan et al., 2007a, b) and organics such as oxalic and malonic acids (Sullivan and Prather, 2007). In a study where filter samples were collected during a dust storm in Beijing and analysed using transmission electron spectroscopy, dust was internally mixed with nitrate (Li and Shao, 2009). Laboratory ice nucleation experiments of MD coated with sulfates/sulfuric acid showed that for a given temperature, ice formation of sulfate coated particles was suppressed in the deposition mode requiring higher $\mathrm{RH}_{\mathrm{i}}$ to activate (Archuleta et al., 2005; Cziczo et al., 2009; Eastwood et al., 2009) and depending on particle size, smaller coated particles $\leq 100 \mathrm{~nm}$ required homogeneous freezing conditions to nucleate ice (Archuleta et al., 2005). Similarly, for large MD cores immersed in ammonium sulfate solution drops, heterogeneous freezing was observed, however, for droplets with cores $\leq 100 \mathrm{~nm}$, homogeneous freezing temperatures $(\sim 235 \mathrm{~K})$ were required for ice formation 
(Hung et al., 2003). Deposition freezing was also found to be greatly suppressed when ATD particles were coated with sulfuric acid requiring water saturated conditions for ice formation and resulting in a lower fraction of particles activating ice compared to uncoated ATD (Sullivan et al., 2010b). Sulfuric acid coated ATD particles were also observed to freeze via immersion mode at water saturation at $T>230 \mathrm{~K}$, i.e. at higher $\mathrm{RH}_{\mathrm{w}}$ compared to non-preactivated uncoated ATD particles (Knopf and Koop, 2006). Immersion freezing of $300 \mathrm{~nm}$ ATD particles showed a change in onset freezing temperature from 245 to $239 \mathrm{~K}$ when particles were coated with sulfuric acid (Niedermeier et al., 2011a, b). Ice nucleation of ATD particles exposed to nitric acid vapour (Sullivan et al., 2010a), showed impeded ice formation in the deposition mode and no effect of suppression in the condensation mode but rather sub-saturated condensation freezing was initiated at RHs just below water saturation (98\%). Kanji et al. (2008) found that octyl-coated silica particles impede ice nucleation in the deposition mode to beyond instrument detection limits compared to uncoated silica particles. Möhler et al. (2008) showed that coating illite particles with a surrogate of secondary organic aerosol (SOA) suppressed the ice nucleation ability in the deposition mode with the coated particles requiring $40 \%$ higher $\mathrm{RH}_{\mathrm{i}}$ than the uncoated particles. The above studies consistently observed that deposition ice formation is suppressed due to processes that mimic atmospheric chemical ageing of MD particles. However, Wang et al. (2012) found that ambient particles composed of organic coatings with soot or inorganic inclusions collected in the Los Angeles area exhibited immersion mode ice nucleation for temperatures between $231-252 \mathrm{~K}$ and $\mathrm{RH}_{\mathrm{w}}=90-100 \%$. From the same field study conducted in and around Mexico City, particles with dust and sulfate species coated with thin and thick layers of secondary organics did not show significantly different deposition mode ice formation onsets in the temperature range $230-205 \mathrm{~K}$ indicating that the level of ageing did not matter for ice formation onsets which were found to be in the range $\mathrm{RH}_{\mathrm{w}}=70-90 \%$ (Knopf et al., 2010). In a study conducted at a mountain-top site in Colorado (Storm Peak, $3210 \mathrm{~m}$ a.s.l.), ice crystal residual compositions were found to be enriched in minerals, however, the most iceactive aerosol at $210<T<230 \mathrm{~K}$ and $104<\mathrm{RH}_{\mathrm{i}}<140 \%$ was found to contain detectable amount of organic material that had oxygen signatures (Baustian et al., 2012). This is in contrast to what one would expect for internally mixed particles in the deposition mode base on the laboratory measurements, suggesting that proxies used in the laboratory may not fully represent atmospheric compositions.

The previously discussed field studies by DeMott et al. (2003a), Cziczo et al. (2004) and Richardson et al. (2007) report the majority of MD particles in ice crystal residuals were not internally mixed with sulfates or organics. A study by Twohy and Poellot (2005) where ice crystal residuals were sampled from anvil cirrus clouds onto filters and analysed by transmission electron microscopy also showed that the in- dustrial and mineral dust categories were not mixed with sulfate and organics. It is therefore reasonable to conclude that laboratory studies of ice nucleation using bare mineral dust particles is of significant importance to understanding heterogeneous ice nucleation (Cziczo et al., 2004). The single mass spectrometric techniques used to investigate the mixing state of ice crystal residuals and aerosols are not sensitive to surface functional groups. Since MD is largely composed of oxides (mainly alumina and silica), one cannot eliminate the possibility of aerosol processing and oxidation reactions that would lead to modification of the MD surface functional groups from exposure to trace gasses such as $\mathrm{O}_{3}$ (Cwiertny et al., 2008).

Ozone is an important trace gas in the troposphere with an annual source of $3700-5400 \mathrm{Tg} \mathrm{yr}^{-1}$ and concentrations ranging from as low as $5 \mathrm{ppbv}$ near the surface in clean regions up to about $120 \mathrm{ppbv}$ in the upper troposphere in midlatitudes. Global 3-D models have shown ozone concentration decreases by up to $10 \%$ in dust source or nearby regions (Dentener et al., 1996). An airborne field study report reduced ozone mixing ratios within North African dust layers suggesting a loss of 4 ppbv $_{3}$ day $^{-1}$ (de Reus et al., 2000). A number of laboratory studies have shown that in the presence of MD or metal oxide surfaces, $\mathrm{O}_{3}$ is lost to the particle surfaces (Roscoe and Abbatt, 2005; Chang et al., 2005; Sullivan et al., 2004; Usher et al., 2003b; Michel et al., 2002, 2003; Hanisch and Crowley, 2003; Li and Oyama, 1998; Li et al., 1998; Karagulian and Rossi, 2006; Mogili et al., 2006). In particular in the work of Roscoe and Abbatt (2005) it was shown that the exposure of dry alumina to $\mathrm{O}_{3}$ resulted in an irreversible stable IR absorption feature that was assigned to an $\mathrm{M}=\mathrm{O}$ type functional group, where the $\mathrm{M}$ is a strong Lewis acid surface site with an anion vacancy on the alumina surface presenting evidence for a surface oxide species forming. A surface peroxide species formation was reported from Raman spectroscopy of manganese oxide exposed to $\mathrm{O}_{3}$ presenting additional evidence of surface modification due to $\mathrm{O}_{3}$ exposure (Li et al., 1998; Li and Oyama, 1998).

Given the tropospheric abundance of $\mathrm{O}_{3}$, the long residence time and transport range of mineral aerosol, and the known interactions between $\mathrm{O}_{3}$ and mineral particles, we present the ice nucleation properties of surrogates of atmospheric MD that have been exposed to $\mathrm{O}_{3}$ at low and high concentration. In this work we address three specific questions: first, does the ice nucleation activity of the $\mathrm{O}_{3}$ aged particles change and how? Second, is the effect uniform across different MD species and ice nucleation mechanisms? Third, is the effect dependent on the amount of ozone exposure? In order to answer these questions we compare the IN activity of untreated Ka and ATD in the deposition and immersion mode to that of $\mathrm{O}_{3}$ aged $\mathrm{Ka}$ and ATD subjected to high and low $\mathrm{O}_{3}$ exposures. 


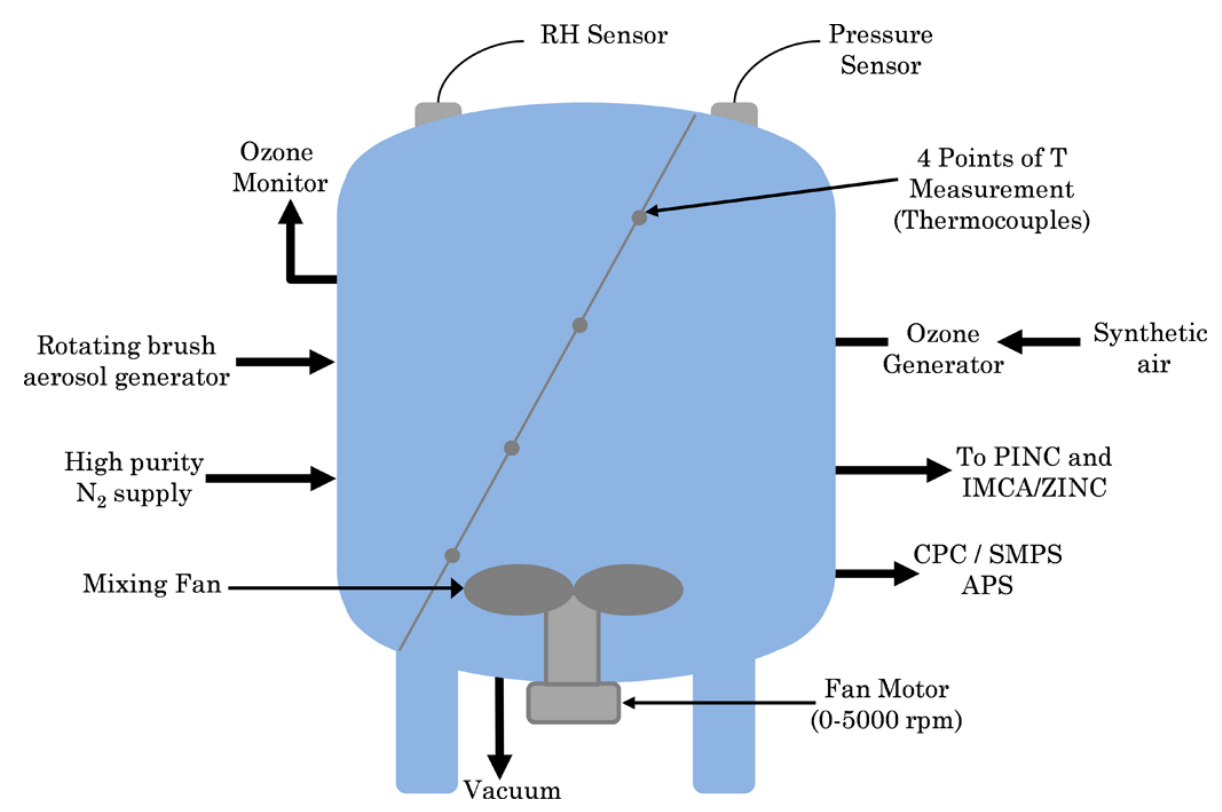

Fig. 1. Schematic of the experimental set-up around the stainless steel aerosol tank. The dimensions given in the text for the tank are taken at the centre of the tank, these are not uniform since the tank has curved edges.

\section{Experimental methods overview}

A single component mineral substance, kaolinite (Ka) and a desert dust representing a mixture of components, Arizona Test Dust (ATD), were used in this work. Polydisperse $\mathrm{Ka}$ particles (KGa-1b, Clay Mineral Society, $\mathrm{Al}_{4}(\mathrm{OH})_{8} \mathrm{Si}_{4} \mathrm{O}_{10}$, density $\left.=2.2 \mathrm{~g} \mathrm{~cm}^{-3}\right)$ and ATD particles (fine dust, $0-3 \mu \mathrm{m}$ nominal size, Powdered Technology Inc., density $=2.65 \mathrm{~g} \mathrm{~cm}^{-3}$ ) were suspended in a $2.78 \mathrm{~m}^{3}$ cylindrical stainless steel aerosol tank with a diameter of $1.49 \mathrm{~m}$ in the middle of the tank and height of $1.91 \mathrm{~m}$ as shown in Fig. 1. The purchased ATD sample is milled, washed and baked at high temperature in its production process while the KGa-1b particles after being collected from their field source deposits, undergo low temperature drying only. Inside the aerosol tank, particles can be exposed to various levels of $\mathrm{O}_{3}$ (described in Sect. 3.1). Immersion freezing measurements of un-aged and $\mathrm{O}_{3}$-aged particles were conducted for $232 \mathrm{~K}>T>264 \mathrm{~K}$ with a combination of the IMCA-ZINC (IMmersion ChAmber - Zurich Ice Nucleation Chamber) that has been described in detail in Lüönd et al. (2010) and Welti et al. (2012). Deposition mode experiments of the same particles were conducted for $232<T<252 \mathrm{~K}$ with the Portable Ice Nucleation Chamber (PINC) described in detail in Chou et al. (2011). By measuring the aerosol size distributions in the stainless steel tank, ice crystal numbers in PINC and the droplet/ice crystal ratio in IMCA-ZINC, we are able to report ice activated fractions as well as $n_{\mathrm{S}}(T)$ of $\mathrm{Ka}$ and ATD.

\subsection{Aerosol generation and processing}

A stainless steel aerosol tank housed dry suspended Ka, BET (gas adsorption) surface area $11.8 \pm 0.8 \mathrm{~m}^{2} \mathrm{~g}^{-1}$ (Murray et al., 2011) or ATD particles, BET surface area $5.7 \mathrm{~m}^{2} \mathrm{~g}^{-1}$ (Wagner et al., 2008). The tank has 20 connecting ports made up of $16 \mathrm{KF} 40$ and $4 \mathrm{CF} 200$ flanges that can be used to couple various instruments for analysis and characterization. One of the 16 ports is used for a direct connection to the IN counters, PINC and IMCA-ZINC while others are used for the aerosol monitoring instruments. The larger connection ports were not utilised for the current work. The aerosol tank also has a motor on the outside to operate a mixing fan inside the tank that can be run at varying speeds from $0-5000 \mathrm{rpm}$. A schematic of the aerosol tank is shown in Fig. 1. A variety of aerosol and ambient monitoring instruments were coupled to the tank such as the Aerodynamic Particle Sizer (TSI Inc., APS 3221), Condensation Particle Counter (TSI Inc., CPC 3772) and Scanning Mobility Particle Sizer (SMPS, TSI Inc., Electrostatic Classifier 3080, DMA 3081, CPC 3010 with an impactor $0.071 \mathrm{~cm}$ ). In addition, a relative humidity sensor (Tetra Tec Instruments, MFQ12), pressure transducer (MKS, Full Scale $1000 \mathrm{mb}$ ) and 4 type $\mathrm{K}$ thermocouple sensors that are mounted on a taut wire which is mounted in a vertical but diagonally oriented fashion inside the aerosol tank to monitor the temperature homogeneity. To produce $\mathrm{O}_{3}$, the tank is connected to a variable efficiency (40-100\% conversion) corona discharge $\mathrm{O}_{3}$ generator (Taoture International Enterprises Inc., Generator 1000 BT-12) that is fed by a $1 \mathrm{lpm}$ high purity synthetic air supply (purity 5.6). An automatic $\mathrm{O}_{3}$ transmitter (Aeroqual 

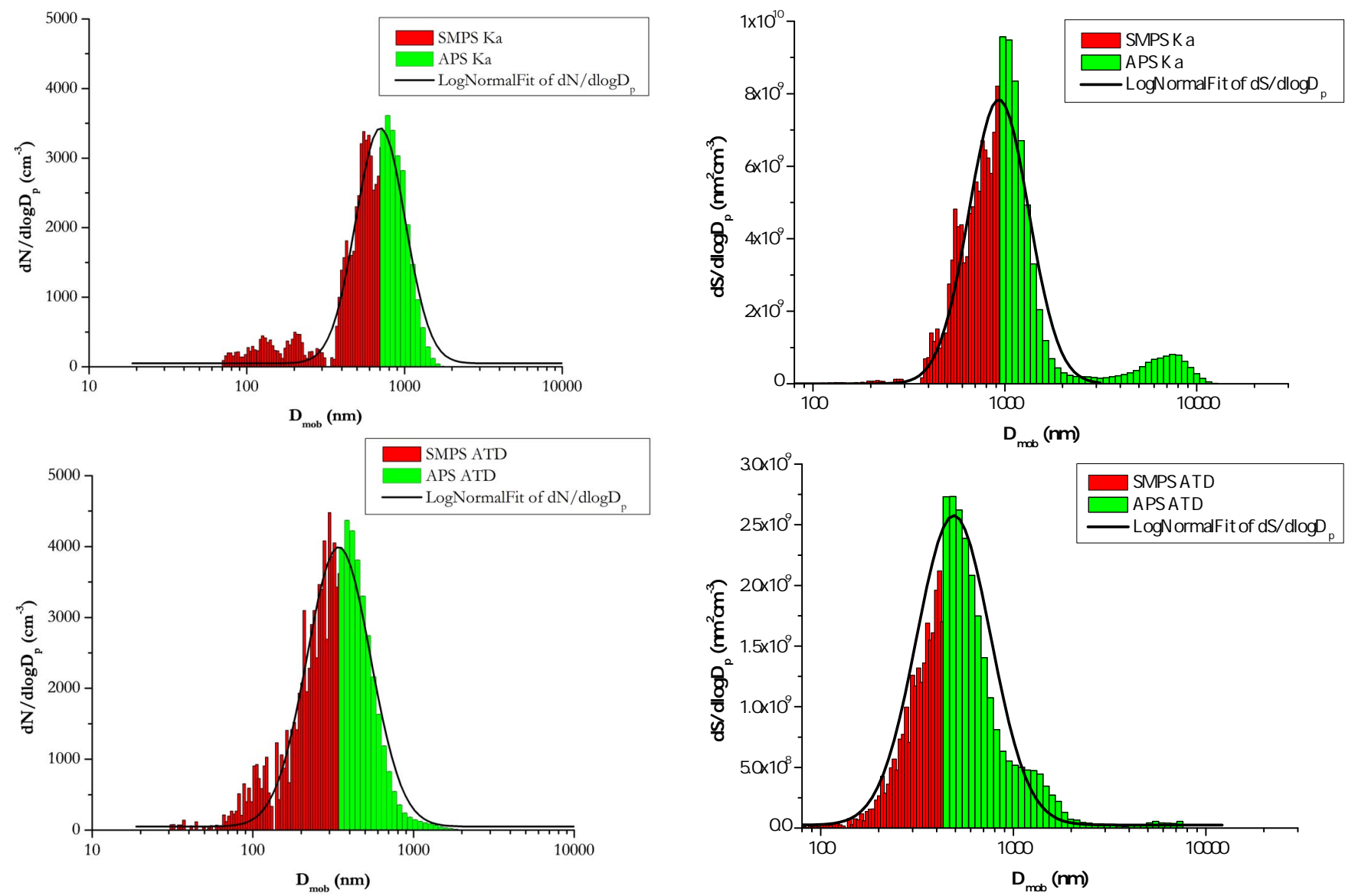

Fig. 2. Representative number size distributions for Ka (top) and ATD (bottom) of suspended dust particles in aerosol tank recorded with an SMPS and APS simultaneously. We note that IN counters sampled through a $1 \mu \mathrm{m}$ impactor necessitating the use of particle number distributions of less than $1.14 \mu \mathrm{m}$ aerodynamic diameter for ice-active fraction calculations.

series 940-03, Full Scale $0.500 \mathrm{ppm}$ ) equipped with an internal pump sampled $100 \mathrm{sccm}$ of air from the tank to obtain $\mathrm{O}_{3}$ concentrations at a time resolution of $30 \mathrm{~s}$. In order to conduct ice nucleation experiments of particles un-aged particles, the tank was "cleaned" by evacuating it to pressures of less than 1 mbar using a vacuum pump (Pfeiffer Vacuum, UNO 65) and refilled with ultra high purity $\mathrm{N}_{2}$ (purity 6.0) consecutively (3-4 times) so as to reduce background particle counts in the tank to below $1 \mathrm{~cm}^{-3}$. To achieve this background, 3-4 successive evacuation and refill runs were required, whereas to further reduce the concentration to about $10^{-2} \mathrm{~cm}^{-3}$ the tank was purged over $48 \mathrm{~h}$ with a $0.6 \mathrm{lpm}$ flow of $\mathrm{N}_{2}$. Typically the slow purge is only conducted if the aerosol species being sampled was being changed. Commercially available samples of Ka and ATD were dry suspended by adding particles into the tank to a concentration of approximately $3500 \mathrm{~cm}^{-3}$ with a rotating brush generator (Palas, RBG 1000) via a cascade of two cyclones that con- fined the size distribution to mostly below $1 \mu \mathrm{m}$. During the filling procedure the CPC measurements are initiated to monitor particle concentration and immediately after the SMPS and APS measurements are conducted to obtain size and concentration distribution data. Representative sample number and surface distributions of both Ka and ATD approximately fit log-normal distributions and are shown in Figs. 2 and 3, respectively. We used previously published methods (DeCarlo et al., 2004; Jennings, 1988) to merge SMPS with APS data to convert aerodynamic to mobility diameter. For Ka the size range (diameter) of the particles was $0.1-2.0 \mu \mathrm{m}$ with a mode of $0.8 \mu \mathrm{m}$ and for ATD, $0.05-2.0 \mu \mathrm{m}$ with a mode of $0.4 \mu \mathrm{m}$.

To age the Ka and ATD particles before conducting IN measurements, the tank is cleaned to reduce background concentrations before $\mathrm{O}_{3}$ was introduced into the $\mathrm{N}_{2}$ filled tank. Ozone was generated at a $40 \%$ conversion efficiency setting for 20-30 s divided up into 5-10 s spurts over a few minutes to allow for sufficient mixing time in the tank and for 


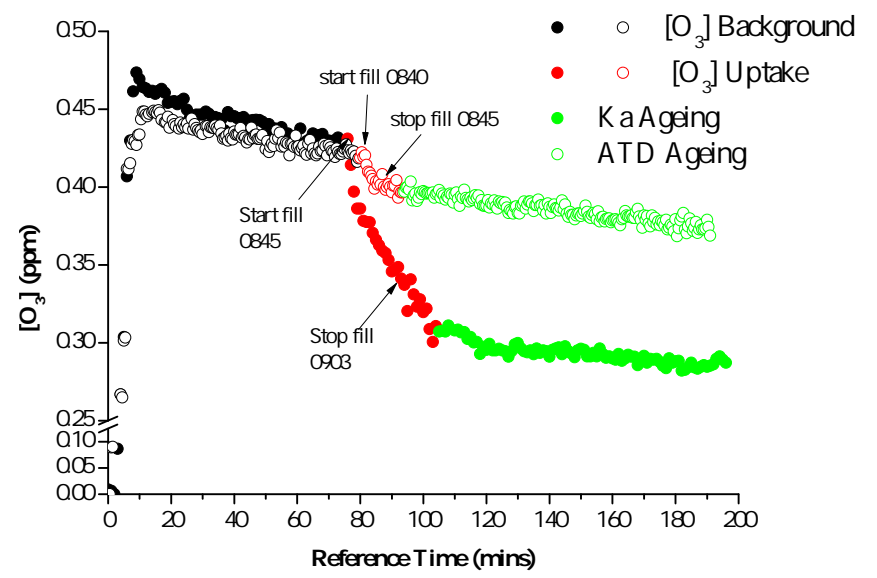

Fig. 4. Time series for $\mathrm{O}_{3}$ ageing experiments in the aerosol tank. $\mathrm{O}_{3}$ is added to the tank and a background wall-loss rate is observed. Arrows on the graph indicated start and stop times for filling dust. $\mathrm{O}_{3}$ loss to the particle surface was considered to be first order.

the ozone transmitter to respond with the real-time concentrations. Once an $\mathrm{O}_{3}$ concentration of 460 ppbv was reached, $\mathrm{O}_{3}$ addition was terminated and concentration in the tank was monitored for approximately $80-90 \mathrm{~min}$ in order to obtain the background $\mathrm{O}_{3}$ decay (wall loss rate) as shown in Fig. 4. Aerosol particles are subsequently introduced into the tank until the desired concentration is reached. The particles are allowed to age in the $\mathrm{O}_{3}$ environment for approximately $2 \mathrm{~h}$ before IN sampling begins. $\mathrm{All}_{3}$ ageing experiments of the mineral dust particles were conducted under dry $\left(\mathrm{RH}_{\mathrm{W}}<5 \%\right)$ and dark conditions at stable room temperature of $296 \mathrm{~K}$ with a variation of up to $0.2 \mathrm{~K}$ along the height of the aerosol tank. Using the $\mathrm{O}_{3}$ concentrations and aerosol mass concentrations obtained from the SMPS and APS, we determined the wallloss of $\mathrm{O}_{3}$ and uptake onto the dust particles. Experiments where the dust particles were exposed to high concentrations of $\mathrm{O}_{3}$ of 1.4 ppmv and 4 ppmv were also conducted. Uptake was on the order of 30-130 ppbv and only determined for the low concentration ( $460 \mathrm{ppbv}$ ) experiments since the instrument used to monitor real-time $\mathrm{O}_{3}$ concentrations had an upper limit of 500 ppbv. This uptake onto dust was small compared to the large concentrations used for the high exposure experiments and occurred fast, immediately after the addition of the dust to the $\mathrm{O}_{3}$ filled tank. For the high exposure experiments, we injected a known amount of $\mathrm{O}_{3}$ (calculated from air flow, time and conversion efficiency of the $\mathrm{O}_{3}$ generator), and aged the particles for the same time as in the low exposure experiments. Based on the low concentration exposures and previously reported literature (see sections below) we assume that under these conditions $\mathrm{O}_{3}$ is still lost to the particle surface but with different kinetic parameters and possibly different loss mechanisms. We note that determining $\mathrm{O}_{3}$ uptake coefficients is not the focus of the current work, we present them in Sect. 4.1 to validate the $\mathrm{O}_{3}$ uptake observed here and to compare our values to the large body of data that already exist in the literature which focused on the kinetics and mechanisms of $\mathrm{O}_{3}$ uptake onto MD (Usher et al., 2003a; Cwiertny et al., 2008 and references therein).

\subsection{Ice nucleation measurements}

Immersion and deposition mode IN counters were used to sample particles from the top of the aerosol tank. The IN counters are of the continuous flow diffusion chamber (CFDC) design based on the original thermal gradient diffusion chamber principle (Rogers, 1988) and have been extensively described in previous work (Chou et al., 2011; Lüönd et al., 2010). An overview of their operation and ice detection is presented in the following sections.

\subsubsection{Deposition nucleation experiments with PINC}

Deposition mode experiments were carried out with a CFDC that is compact and designed for field and portable applications. PINC is a parallel plate vertically oriented chamber with a distance of $10 \mathrm{~mm}$ between the two walls of the chamber and has been used and described extensively in previous work (Chou et al., 2011, 2013). Briefly, an aerosol layer is sandwiched between two particle-free sheath flows in the chamber whose inner walls are coated with ice and held at different temperatures. The total flow rate in the chamber is $10 \mathrm{lpm}$ with the aerosol and particle-free sheath flows maintained at $1 \mathrm{lpm}$ and $2 \times 4.5 \mathrm{lpm}$, respectively, on either side of the aerosol layer. The sheath flow constricts the sample to a known position between the two walls with reasonable accuracy in order to determine the sample temperature and RH. Increasing the difference in temperature between cold and warm walls results in a linear gradient of water vapour pressure between the walls and the $\mathrm{RH}$ along the gradient can be calculated. A typical experiment is conducted by keeping the sample temperature constant while increasing the $\mathrm{RH}$ the particles are exposed to at a rate of $2.5-4 \% \mathrm{RH}_{\mathrm{W}} \mathrm{min}^{-1}$ from $\mathrm{RH}_{i}=100$ to above water saturation. By knowing the position of the aerosol layer, it is possible to determine the $\mathrm{RH}$ the particles are exposed to. Particles that nucleate ice are detected by an optical particle counter (OPC, Climet 3100) that differentiates ice crystals from background particles based on particle size. We use the size bins for particles greater than $3 \mu \mathrm{m}$ to count ice crystals. The sample flow enters the main chamber (growth section) through a particle impactor with an aerodynamic diameter cut-off, $d_{50}$ of $1 \mu \mathrm{m}$. This is necessary to cut out large particles that could be miscounted as ice by the OPC. The particles have a residence time of $7 \mathrm{~s}$ in the growth section after which the sample flow passes through an evaporation section (held at $\mathrm{RH}_{\text {ice }}=100 \%$ ) for $2 \mathrm{~s}$ before exiting the chamber through the OPC. The evaporation section ensures that any water drops that may have nucleated will evaporate preventing anomalous ice counts by the OPC. In the current work, PINC was operated for deposition mode sampling in the range $253-232 \mathrm{~K}$ with a 
maximum corresponding sampling $\mathrm{RH}$ with respect to water $\left(\mathrm{RH}_{\mathrm{w}}\right)$ of $104-112 \%$. The maximum $\mathrm{RH}$ is the point beyond which water droplets grow large enough to survive the evaporation section in sizes not distinguishable from ice crystals and is referred to as the water droplet survival line as shown in Fig. 5. Aerosol sample concentrations decayed over the course of a sampling day due to settling and wall-losses in the tank, from $\sim 3500$ to 700 particles $\mathrm{cm}^{-3}$ which corresponds to $350-70$ particles $\mathrm{cm}^{-3}$ in the CFDC when the dilution of sheath to sample flows is accounted for. The number of particles sampled by the CFDC was well below the maximum concentration of 7500 particles $\mathrm{cm}^{-3}$ that would be required to cause any water vapour depletion in PINC. This limit was determined by considering the conditions it would take to completely consume the water vapour in a $1 \mathrm{~cm}^{3}$ volume of air at $243 \mathrm{~K}$ and $\mathrm{RH}_{\mathrm{w}}=100 \%$ assuming depletion to spherical ice particles of diameter $5 \mu \mathrm{m}$. Particle coincidence errors in the CPC/OPC only occur at 10000 particles $\mathrm{cm}^{-3}$ and are therefore not a concern in the current work.

\subsubsection{Immersion freezing experiments with IMCA-ZINC}

Immersion mode freezing experiments were conducted using a CFDC instrument that has been described in detail elsewhere (Lüönd et al., 2010; Welti et al., 2012). This instrument is divided into two parts, first the droplet activation of the dust particles and second the freezing section. The first part, IMCA, consists of two vertically oriented parallel plates that are $5 \mathrm{~mm}$ apart in which dust particles are forced to act as condensation nuclei. The chamber walls are lined with continuously wetted filter paper and held at $323.2 \mathrm{~K}$ at the warm and $303.2 \mathrm{~K}$ at the cold wall in order to maintain $\mathrm{RH}_{\mathrm{w}}=110 \%$ at 313.2 at the sample position. An aerosol flow of $1 \mathrm{lpm}$ is sandwiched between particle-free sheath air of $2 \times 2 \mathrm{lpm}$ (total flow rate of $5 \mathrm{lpm}$ in IMCA). The residence time in IMCA is $8 \mathrm{~s}$ which produce droplets of approximately $10 \mu \mathrm{m}$ in diameter. After the droplet activation, the particles are cooled in the lower part of IMCA just before being introduced into ZINC (Stetzer et al., 2008), the second part of the immersion freezing instrument. ZINC is also a vertically oriented parallel plate chamber whose internal walls are $10 \mathrm{~mm}$ apart, coated with ice and held at temperatures such that the aerosol layer is held at the desired temperature of observation for immersion freezing. Before the particles enter ZINC an additional sheath flow of $2 \times 2.5 \mathrm{lpm}$ is added, thus bringing the total flow rate in ZINC to $10 \mathrm{lpm}$ with a residence time of just over $10 \mathrm{~s}$ in the supercooled region relevant for ice nucleation. The $\mathrm{RH}_{\mathrm{w}}$ in ZINC is maintained at $100 \%$ so as to avoid the evaporation of or condensation onto the droplets.

In the current work, ZINC operates in an almost identical fashion to PINC except for ice detection. For the IMCAZINC experiment ice detection is achieved with the Ice Optical DEtector (IODE) described in Nicolet et al. (2010). The IODE detector is mounted at the upper end of the ZINC evaporation section. IODE is a single particle instrument and therefore it is necessary not to have large particle concentrations in order to avoid coincidence errors in the depolarization ratios measured. In this work an average of 150300 particles $\mathrm{cm}^{-3}$ was used in the immersion freezing experiments. Particles sampled by IMCA also passed through a $1 \mu \mathrm{m}$ impactor to be consistent with particle sizes sampled by PINC. The detector used in IMCA is also sensitive to unactivated particles that are larger than $2 \mu \mathrm{m}$ and potentially miscounts them as ice crystals.

IODE actively discriminates between ice crystals and liquid drops based on the principle that backward scattering on ice crystals will partly change the polarisation of linear polarized incident light whereas spherical water droplets will not. IODE is an in-house self developed detector that has been tested and characterised as well as used for previous ice nucleation studies (Lüönd et al., 2010; Welti et al., 2012; Ladino et al., 2011; Nicolet et al., 2010). The single plane parallel polarized laser light is aligned to the sample layer passing through ZINC and particles are classified to be ice crystals or water droplets due to the intensity of parallel and perpendicular polarized components of backscattered laser light. The signal collected is corrected for background signal from aerosol-free flow from the IODE detector that can come from reflections within the ice chamber and internal reflections within IODE. More details about the detection and signal collection with IODE can be found in Lüönd et al. (2010). Uncertainties are addressed in the following section.

\subsection{Instrument and measurement uncertainties}

The uncertainties in all the measurements reported have been determined through error propagation based on individual instrument uncertainties. All data points shown are an average of 2-4 repeated experiments, therefore instrument uncertainties are plotted as error bars. For all derived parameterizations we have included the error bar weighing when determining the fits. The relative uncertainties in particle concentrations reported from the CPC and OPC are both $10 \%$. The uncertainty in RH reported for PINC and ZINC for the temperature range relevant to this work is $\pm 2 \%$ (Chou et al., 2011) which mostly comes from the uncertainty in temperature measurement of $\pm 0.1 \mathrm{~K}$ and the corresponding equilibrium vapour pressures of ice and water. This uncertainty results in a temperature variation across the aerosol lamina of $\pm 0.4 \mathrm{~K}$. The uncertainty in ice-active fractions (AF) for the deposition mode data is $\pm 14 \%$ (error bars plotted in Fig. 7). The background ice counts in PINC (detection limit) were found to be on the order of $4 \mathrm{~L}^{-1}$. For the immersion freezing data, the frozen fractions are based on individual particle counts and each frozen fraction is the result of classifying between 2000-3000 particles into the ice or droplet categories. The classification of ice or water is based on a threshold depolarization in IODE. If this threshold is met, then a particle is classified as ice. However if the depolarisation signal of 
the particle is within $1 \sigma$ standard deviation of this threshold, then the particle counted is potentially misclassified. The uncertainty in frozen fraction which we also refer to as activated fraction, AF (see error bars in Fig. 8) is therefore the ratio of potentially misclassified droplets ( + error) or ice crystals ( - error) to the total number of detected particles. As such for each frozen fraction detected, the uncertainty varies. For additional details on the signal analysis we refer readers to Lüönd et al. (2010). The uncertainties in $n_{\mathrm{s}}(T)$ are propagated from the uncertainties in the optical detection methods (OPC and IODE) and the aerosol counting instruments (CPC/SMPS) and shown as error bars in Figs. 9 and 10. Lastly, the measurement uncertainty from the $\mathrm{O}_{3}$ transmitter in the concentration range $0.001-0.5 \mathrm{ppm}$ is reported to be $\pm 2-5 \%$.

\section{Results}

\subsection{Ozone ageing experiments}

We present $\mathrm{O}_{3}$ surface coverages and uptake coefficients to compare our results to the literature to show consistency of results obtained. The surface coverage serves to indicate the amount of $\mathrm{O}_{3}$ that is destroyed per unit surface area of dust particulates, i.e. the number of sites capable of interacting with $\mathrm{O}_{3}$ (Hanisch and Crowley, 2003). Time series of $\mathrm{O}_{3}$ decay from two experiments, one with $\mathrm{Ka}$ and the other with ATD in the absence of particles (wall loss) and presence of particles is shown in Fig. 4. There is a larger loss of $\mathrm{O}_{3}$ in the presence of the MD which could be attributed to either reactive uptake or catalytic destruction (Sullivan et al., 2004). From the data obtained here (red points in Fig. 4) we deduced rate constants of $\mathrm{O}_{3}$ decay by assuming first order $\mathrm{O}_{3}$ loss to the MD particles (Chang et al., 2005; Sullivan et al., 2004; Karagulian and Rossi, 2006; Usher et al., 2003a, b; Michel et al., 2003; Hanisch and Crowley, 2003; Michel et al., 2002). The absolute uptake of $\mathrm{O}_{3}$ was derived (see Eq. 1) by taking the difference in concentrations between the background period (black points) and the ageing period where the $\mathrm{O}_{3}$ loss rate had returned to that in the absence of particles (green data points in Fig. 4). This was repeated for 2 additional ageing experiments for each $\mathrm{Ka}$ and ATD. From the amount of $\mathrm{O}_{3}$ lost to the MD particles and the BET surface area of Ka and ATD, we determined the active surface site coverage of $\mathrm{Ka}$ and ATD using the following equation:

surface coverage $=\frac{\left[\mathrm{O}_{3}\right]_{\text {uptake }}\left(\text { molecules } \mathrm{cm}^{-3}\right)}{\mathrm{SA}_{\text {aerosol }}\left(\mathrm{cm}^{2} \mathrm{~cm}^{-3}\right)}$.

The $\mathrm{O}_{3}$ surface coverage (Table 1) is higher for ATD than is for $\mathrm{Ka}$, contrary to what one would expect from observing the data in Fig. 4 which shows the net uptake was lower on the ATD samples. However, the BET surface area of $\mathrm{Ka}$ is a factor of two more than ATD. The values in this work are on the order of $10^{15}$ and $10^{16}$ molecules $\mathrm{cm}^{-2}$ for $\mathrm{Ka}$ and $\mathrm{ATD}$, respectively, whereas the number typical for the maximum number of sites available on a hexagonally closed-pack crystal such as Ka and metal oxides (silica and alumina) which form $85 \%$ of the ATD composition is roughly $10^{15}$ sites cm $^{-2}$ (Michel et al., 2002). Assuming one $\mathrm{O}_{3}$ molecule interacts per surface site, the $\mathrm{O}_{3}$ coverage reported here for ATD suggests the surface does not saturate immediately, rather it first displays catalytic destruction of $\mathrm{O}_{3}$ since more $\mathrm{O}_{3}$ molecules are taken up (destroyed) than there are active sites. For Ka, the surface coverage of $10^{15}$ molecules $\mathrm{cm}^{-2}$ is similar to the number of active sites $\left(10^{15}\right.$ sites $\left.\mathrm{cm}^{-2}\right)$ expected to be available suggesting that saturation occurs within a single interaction hence the surface active sites are not regenerated during uptake (Michel et al., 2002; Sullivan et al., 2004).

Using the method described in Cwiertny et al. (2008) and the rate constant from the initial first order loss of $\mathrm{O}_{3}$ on the dust $\left(k_{\mathrm{obs}}\right)$, we determined initial uptake coefficients using the following relationship:

$k_{\mathrm{obs}}=\frac{\gamma c_{\mathrm{O}_{3}} S_{\mathrm{BET}} C_{\mathrm{mass}}}{4}$,

where $\gamma$ is the initial uptake coefficient, $c_{\mathrm{O}_{3}}$ is the mean speed of $\mathrm{O}_{3}\left(392 \mathrm{~m} \mathrm{~s}^{-1}\right), C_{\text {mass }}\left(\mathrm{g} \mathrm{m}^{-3}\right)$ is the mass concentration of the aerosol species taken from the peak concentration aerosol distributions using the densities given in Sect. 3 and $S_{\text {BET }}$ is the BET surface area $\left(\mathrm{m}^{2} \mathrm{~g}^{-1}\right)$ given in Sect. 2.1. Results are listed in Table 1. The use of Eq. (2) is justified because of the negligible gas phase diffusion limitations (Chang et al., 2005) for the $\mathrm{O}_{3}$ concentrations used here.

The uptake coefficients determined here are comparable to those obtained in previous kinetic studies of $\mathrm{O}_{3}$ uptake on MD particles also based on BET surface areas. Michel et al. (2003) report an uptake coefficient for Ka of $(3 \pm 1) \times 10^{-5}$ which is comparable to the values we obtain for Ka listed in Table 1. Hanisch and Crowley (2003) report an uptake coefficient of $1.2 \times 10^{-4}$ for Saharan dust which also compares well to the values listed in Table 1 for ATD. Despite the different source of dusts here, we note that ATD shares a major component, quartz $\left(\mathrm{SiO}_{2}\right)$ with Saharan dust. Arizona Test Dust also contains iron (iii) oxide which has been reported to have an uptake coefficient of $(1.8 \pm$ $0.7) \times 10^{-4}$ (Usher et al., 2003a) and is also comparable to our values for ATD. For a detailed compositional analysis of ATD see Vlasenko et al. (2005). Furthermore, an uptake coefficient for ATD of $(2.5 \pm 1.2) \times 10^{-3}$ has been reported for an initial $\mathrm{O}_{3}$ concentration of $8 \times 10^{12}$ molecules cm $\mathrm{cm}^{-3}$ (Karagulian and Rossi, 2006). Given that our initial concentrations are on the order of $1 \times 10^{13}$ molecules $\mathrm{cm}^{-3}$ (430 ppbv) and we have an order of magnitude lower uptake coefficients for ATD (on the order of $10^{-4}$ ), our uptake coefficients are in good agreement in light of previous observations that report uptake coefficients to inversely correlate with initial $\mathrm{O}_{3}$ concentrations since the ratio of $\mathrm{O}_{3}$ molecules 
Table 1. List of kinetic variables calculated from $\mathrm{O}_{3}$ ageing of MD particles. Ozone concentrations indicated in the first column are initial concentrations just before introducing aerosol into the tank but after accounting for background wall loss.

\begin{tabular}{|c|c|c|c|c|}
\hline $\begin{array}{l}\text { Particle and } \\
{\left[\mathrm{O}_{3}\right](\mathrm{ppbv})}\end{array}$ & $\begin{array}{l}\text { 1st order rate constant } \\
\qquad\left(k_{\mathrm{obs}} \min ^{-1}\right)\end{array}$ & $\begin{array}{c}C_{\text {mass }} \\
\left(\mathrm{g} \mathrm{m}^{-3}\right)\end{array}$ & $\begin{array}{c}\text { Active Surface Site } \\
\text { Coverage }\left(\text { molec } \mathrm{cm}^{-2}\right)\end{array}$ & $\begin{array}{c}\text { Average Uptake } \\
(\gamma)\end{array}$ \\
\hline $\mathrm{Ka}+425$ & $(1.42 \pm 0.13) \times 10^{-2}$ & $2.9 \times 10^{-3}$ & $(6.5 \pm 1.0) \times 10^{15}$ & $(7.1 \pm 1.1) \times 10^{-5}$ \\
\hline $\mathrm{Ka}+427$ & $(1.16 \pm 0.05) \times 10^{-2}$ & $3.4 \times 10^{-3}$ & $(6.0 \pm 1.0) \times 10^{15}$ & $(4.9 \pm 0.6) \times 10^{-5}$ \\
\hline $\mathrm{Ka}+430$ & $(1.02 \pm 0.05) \times 10^{-2}$ & $3.4 \times 10^{-3}$ & $(5.5 \pm 0.9) \times 10^{15}$ & $(4.3 \pm 0.6) \times 10^{-5}$ \\
\hline ATD +433 & $(0.44 \pm 0.02) \times 10^{-2}$ & $2.1 \times 10^{-4}$ & $(5.0 \pm 0.8) \times 10^{16}$ & $(6.3 \pm 0.6) \times 10^{-4}$ \\
\hline $\mathrm{ATD}+425$ & $(0.40 \pm 0.05) \times 10^{-2}$ & $5.3 \times 10^{-4}$ & $(1.6 \pm 0.3) \times 10^{16}$ & $(2.3 \pm 0.4) \times 10^{-4}$ \\
\hline
\end{tabular}

taken up by the dust surface to the number of $\mathrm{O}_{3}$ molecules colliding with the surface decreases (Sullivan et al., 2004; Hanisch and Crowley, 2003).

The dry conditions used in this study are atmospherically relevant as it has been shown previously that water vapour does not affect the kinetics and initial uptake coefficient of $\mathrm{O}_{3}$ on MD for both alumina (Sullivan et al., 2004) and authentic Saharan Dust (Chang et al., 2005) lending support to the interaction of $\mathrm{MD}$ with $\mathrm{O}_{3}$ in the atmosphere. Additionally, such interactions on freshly emitted dust are expected to occur in drier parts of the troposphere inside dust plumes or the Saharan Air Layer.

Typical background $\mathrm{O}_{3}$ concentrations in the troposphere are on the order of 30-60 ppbv between $2-11 \mathrm{~km}$ altitudes and in urban regions with high $\mathrm{NO}_{\mathrm{x}}$ sources present, the concentrations can range from $100-400$ ppbv causing serious pollution challenges (Usher et al., 2003a and references therein). For example, during global dust transport in a Saharan Air Layer, it is very common to encounter the altitudes between 2-4 km (Zipser et al., 2009) so that dust particles are exposed to typical $\mathrm{O}_{3}$ concentrations consistently for several days such that ozone depletion onto Saharan dust has directly been observed (de Reus et al., 2000). Prior to being lofted into the upper troposphere, dust can be transported through heavily polluted regions, e.g. Beijing, where it can get exposed to $\left[\mathrm{O}_{3}\right]$ as high as $120 \mathrm{ppbv}$ (Streets et al., 2007).

We extrapolate the exposure time and low $\mathrm{O}_{3}$ concentrations in our work to the atmosphere by estimating a chemical ageing time. We note here that the $\left[\mathrm{O}_{3}\right]$ used in our low exposure studies are a factor of 4-10 higher than encountered in the troposphere. Uptake of $\mathrm{O}_{3}$ onto $\mathrm{MD}$ is known to occur via the Langmuir type mechanism (Usher et al., 2003a) which implies at lower $\left[\mathrm{O}_{3}\right]$, uptake could proceed faster and surface coverage may not approach surface saturation as in the current work. For our low exposure particles aged at initial $\left[\mathrm{O}_{3}\right]$ of $430 \mathrm{ppbv}$ and an exposure time of $130 \mathrm{~min}$ we get a chemical age of $60 \mathrm{ppm}$ min. Assuming an atmospheric background concentration of $45 \mathrm{ppbv}$ in the mid-upper troposphere, the mineral dust particles would need to have a residence time of $\sim 1$ day in order to achieve a similar level of ageing as the low exposure experiments presented here. Our chemical age of 1 day is atmospherically relevant given the long residence times of MD in the atmosphere of up to 12 weeks. To reflect dust transport through a polluted region, we use an $\left[\mathrm{O}_{3}\right]$ of $100 \mathrm{ppbv}$ and the chemical age calculated above is reduced to $9 \mathrm{~h}$ for $130 \mathrm{~min}$ of ageing at $0.43 \mathrm{ppmv}$ of $\mathrm{O}_{3}$. Longer residence times of $\mathrm{MD}$ in the troposphere can result in other species such as organics and sulfates condensing on the particles. During a dust storm, particles can be transported through a polluted urban region where $\left[\mathrm{O}_{3}\right]$ can be 100 ppbv and thus $9 \mathrm{~h}$ could be representative of such an event. For convenience from here on we refer to the untreated particles by their names, Ka and ATD, whereas the low and high $\mathrm{O}_{3}$ exposure particles will be prefixed with LE and $\mathrm{HE}$, respectively.

\subsection{Deposition mode ice nucleation}

In Fig. 5 the onset $\mathrm{RH}_{\mathrm{w}}$ for $0.1 \% \mathrm{AF}$ of $\mathrm{Ka}$ and ATD as a function of temperature for the untreated, LE and HE particles are shown. Hygroscopicity studies have shown that ATD is non-hygroscopic at sub-saturated water conditions (Koehler et al., 2009) for particles with diameters larger than $100 \mathrm{~nm}$ (Vlasenko et al., 2005) which applies to the majority of the ATD particles in this work. Hydrophobic properties of Ka have also been reported through atomic force microscopy measurements (Yin and Miller, 2012). Therefore, it is unlikely that $\mathrm{Ka}$ takes up water at $\mathrm{RH}_{\mathrm{w}}<100 \%$. Data in the region $\mathrm{RH}_{\mathrm{W}}<100 \%$ are therefore interpreted as ice formation via deposition nucleation and condensation freezing for $\mathrm{RH}_{\mathrm{w}}>100 \%$. The Ka particles (Fig. 5a) show no deposition mode activity at $T>240 \mathrm{~K}$ for $0.1 \% \mathrm{AF}$, however at $T<240 \mathrm{~K}$, deposition mode nucleation is active and the onset $\mathrm{RH}_{\mathrm{W}}$ required to activate $0.1 \%$ decreases with decreasing temperature. For $T>240 \mathrm{~K}$ we cannot report condensation freezing unambiguously on Ka particles because $\mathrm{AF}$ of $0.1 \%$ is detected in the water drop survival region where the OPC cannot discriminate between ice and water. Deposition mode studies on Ka reported for onset $\mathrm{RH}_{\mathrm{W}}$ defined at $\sim 0.5-1 \%$ AF found consistently lower $\mathrm{RH}_{\mathrm{w}}$ by 5 $8 \%$ for $233<T<253 \mathrm{~K}$ (Salam et al., 2006) than what we present here. There are however three important differences to note here, first, the mode particle size used in the Salam et al. (2006) study of $1.5 \mu \mathrm{m}$ is significantly larger than the 

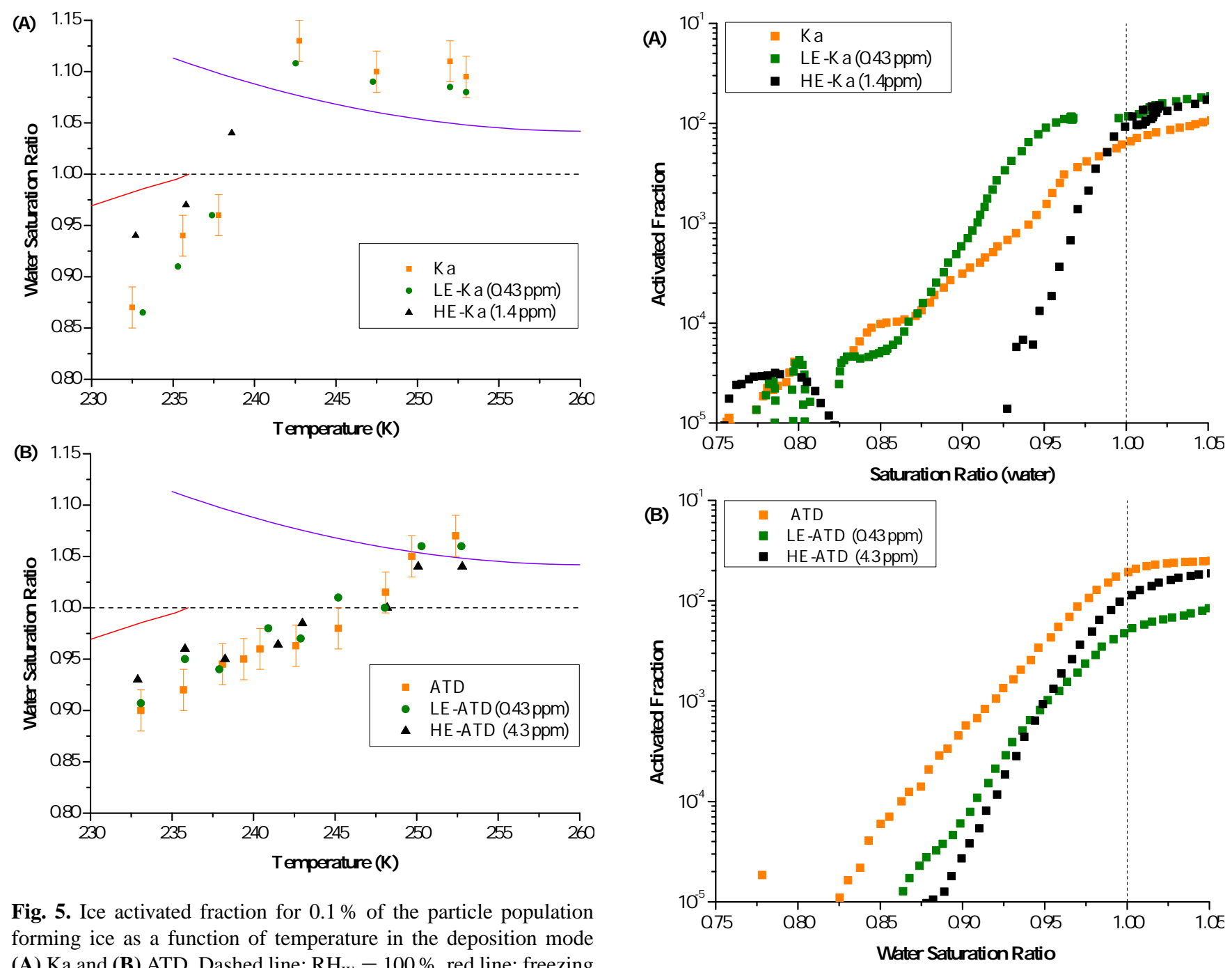

Fig. 5. Ice activated fraction for $0.1 \%$ of the particle population forming ice as a function of temperature in the deposition mode (A) Ka and (B) ATD. Dashed line: $\mathrm{RH}_{\mathrm{W}}=100 \%$, red line: freezing of $0.1 \% 300 \mathrm{~nm}$ aqueous ammonium sulfate particles in $10 \mathrm{~s}$ (Koop et al., 2000; DeMott et al., 2009), purple line: water drop survival line for PINC.

particle size mode used here of $800 \mathrm{~nm}$, thus the higher onset $\mathrm{RH}_{\mathrm{w}}$ in the current work is expected. Second, the residence time in the Salam et al. (2006) work is 20-30 s, which is on the order of 3-4 times more than for PINC which could result in a higher ice fraction being nucleated. Third, the Ka source from the Salam et al. (2006) study is not the same as that used here. Deposition mode data at the $1 \%$ AF level are reported in Welti et al. (2009) for Ka (Fluka) for 100, 200, 400 and $800 \mathrm{~nm}$. Despite the latter size being similar to the mode size of our polydisperse sample, the onset $\mathrm{RH}_{\mathrm{w}}$ are approximately $8 \%$ lower than reported here for $0.1 \% \mathrm{AF}$ at for example, $238 \mathrm{~K}$ indicating that the Fluka sample was much more active than the one used here from Clay Minerals Society. In the temperature range $230-240 \mathrm{~K}$, deposition onset $\mathrm{RH}_{\mathrm{w}}$ of $70-80 \%$ have been reported for Ka (Fluka) particles of average size $3.3 \mu \mathrm{m}$ (Wang and Knopf, 2011) which is about

Fig. 6. Relative humidity scans for Ka (A) and ATD (B) particles performed in PINC for nominal temperature of $236 \mathrm{~K}$. The gap in data for LE-Ka is data missing due to fictitious inflated counts from frost falling off the chamber walls being sampled by the OPC. Dashed line: water saturation.

$15 \%$ lower $\mathrm{RH}_{\mathrm{w}}$ than we report here for the same temperature range. This difference lends further evidence to the effect of size and particle source playing an important role in determining ice nucleation onset. Recent studies have reported that Ka particles from Clay Mineral Society exhibit lower IN activity compared to other commercially available samples (Pinti et al., 2012; Murray et al., 2012) albeit in the immersion mode. Deposition mode studies using the same $\mathrm{Ka}$ as this study have also been reported, however using an environmental scanning electron microscope (ESEM) with larger particle sizes of 1-10 $\mu \mathrm{m}$ (Zimmermann et al., 2007). ESEM is sensitive to the first ice nucleation event out of a particle population and performed with particles on a substrate (cold stage). The combination of the method and the size 

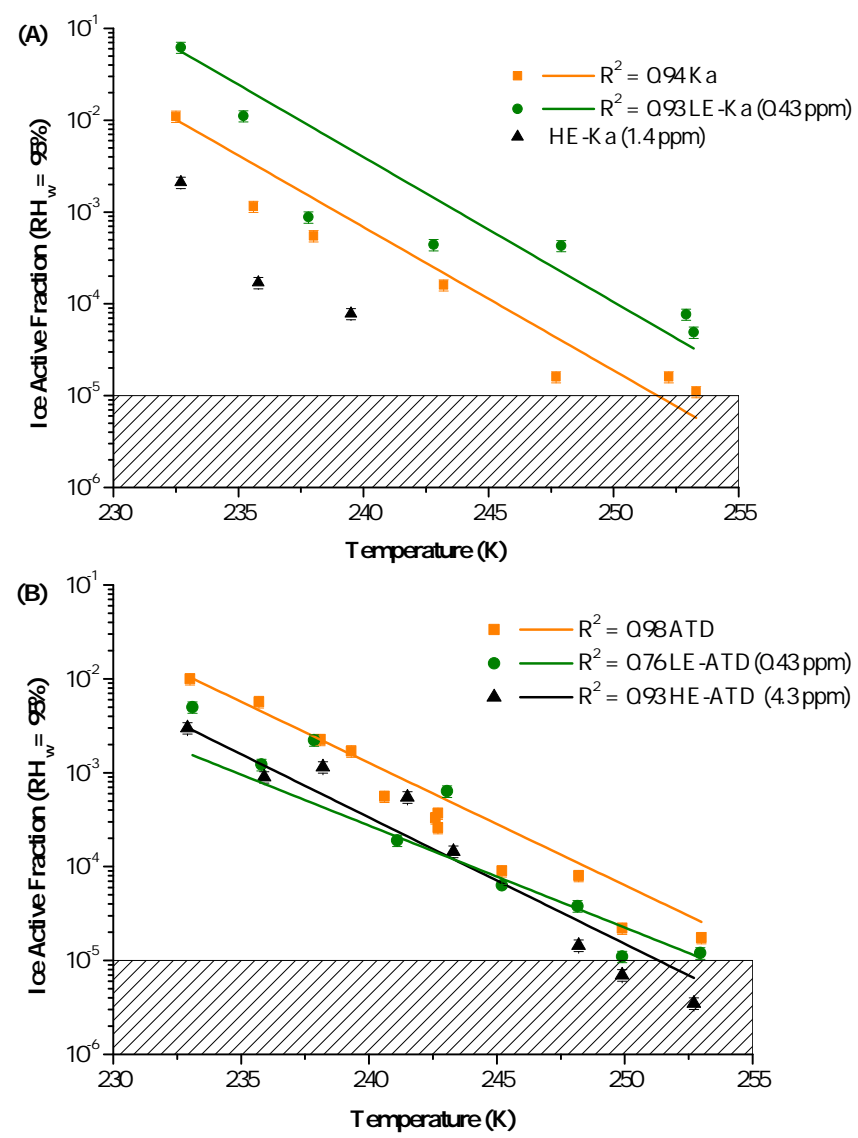

Fig. 7. Ice activated fraction at $\mathrm{RH}_{\mathrm{W}}=95 \%$ as a function of temperature for deposition mode nucleation of (A) Ka and (B) ATD. Exponential fit equations for curves are presented in Table 3. Hashed region represents instrument detection limit for PINC. A fit for the HE-Ka was not calculated obtained because of the few data points collected.

of the particles make it difficult to compare the results and not surprisingly the results from Zimmermann et al. (2007) showed that for Ka particles, deposition nucleation was active at temperatures as warm as $253 \mathrm{~K}$ which is $13 \mathrm{~K}$ higher than observed here.

The data for LE-Ka (green data in Fig. 5a), despite having onset $\mathrm{RH}_{\mathrm{w}}$ that is within the detection uncertainty (except at $\sim 235 \mathrm{~K}$ ), appear at consistently lower onset $\mathrm{RH}_{\mathrm{w}}$. This does suggest a subtle enhancement in ice nucleation of the particles when exposed to $\sim 430 \mathrm{ppbv}$ of $\mathrm{O}_{3}$, with the exception of the data point at $\sim 238 \mathrm{~K}$ which appears to have the same activity as Ka. The HE-Ka show a clear suppression of ice nucleation activity requiring higher onset $\mathrm{RH}_{\mathrm{w}}$ indicating that longer $\mathrm{O}_{3}$ ageing inhibits ice nucleation activity in the deposition mode. Given this suppression trend and the relatively weak ice nucleation activity of Ka at $T>240 \mathrm{~K}$, we did not further explore the ice nucleation activity of the HEKa particles at $T>240 \mathrm{~K}$ as we were limited by instrument detection limits into the water droplet survival region.
The data for $0.1 \%$ AF of ATD particles (Fig. 5b) indicate that deposition mode ice nucleation is active for $T<250 \mathrm{~K}$ above which we observe ice formation in the water saturated region suggesting that Ka is relatively weak at ice nucleation compared to ATD in the deposition mode. Similar deposition mode dependence on temperature has been inferred for ATD in other studies conducted by different IN counters and an expansion chamber where the transition from condensation to deposition modes is reported to occur at $\sim 250 \mathrm{~K}$ (Kanji et al., 2011). In a previous study from our group using ZINC, ATD was also became active in the deposition mode between 250 and $246 \mathrm{~K}$ (Welti et al., 2009). These results suggest that ATD is an efficient IN. Despite this efficiency, in our work at the colder $T \sim 233 \mathrm{~K}$, the onset $\mathrm{RH}_{\mathrm{w}}$ for ATD is $3 \%$ higher than for Ka supporting a higher efficiency of Ka over ATD. This may be surprising given the overwhelming evidence in the literature regarding ATD as being one of the most effective MD samples for ice nucleation (Hoose and Möhler, 2012 and references therein). However, from the size distributions of both the samples it is evident that the larger size mode of $800 \mathrm{~nm}$ for Ka compared to only $400 \mathrm{~nm}$ of ATD, is the likely cause for this earlier onset in ice nucleation on Ka particles (Archuleta et al., 2005; Welti et al., 2009; Kanji and Abbatt, 2010). For ATD at $0.1 \%$ AF there is no significant difference between the aged and un-aged particles at a given temperature since the onset $\mathrm{RH}_{\mathrm{w}}$ of ice formation fall within the instrument uncertainty limits. However, Fig. 5 does not represent the complete ice activation spectra observed since only a cross section of the ice activation spectrum at $\mathrm{AF}=0.1 \%$ is reported. For example, we present plots of the complete activation spectra at $236 \mathrm{~K}$ in Fig. 6 for $\mathrm{O}_{3}$ treated and untreated Ka and ATD. Here we see a clear difference in AF between the aged and un-aged particles in the deposition mode regime (left of the dashed line in Fig. 5) unlike the subtle difference inferred from Fig. 5, between LE, HE and un-aged Ka. For ATD the LE/HE particles have similar activation spectra with both displaying lower activity than ATD in the deposition mode. To better represent this behavior over the entire temperature range studied we present plots where we fix $\mathrm{RH}_{\mathrm{w}}=95 \%$ and plot the $\mathrm{AF}$ as a function of temperature in Fig. 7. By choosing $\mathrm{RH}_{\mathrm{w}}=95 \%$ we ensure that for all temperatures plotted, we remain in the deposition regime, preventing any biases of increased AF from an onset of condensation freezing above water saturation.

The data and corresponding exponential fits (Table 3) plotted in Fig. 7a show that there is a difference in deposition mode activity of the LE-Ka and Ka particles with the former being more efficient IN resulting in greater $\mathrm{AF}$ at a given temperature. The measurements suggest that high $\mathrm{O}_{3}$ exposure to is detrimental to the IN activity of $\mathrm{Ka}$ in the temperature regime studied. It is however surprising that ice nucleation of the LE-Ka and HE-Ka do not respond linearly, i.e. both suppressed or both enhanced, by different magnitudes.

In Fig. 7b data are plotted for ATD with fits reported in Table 3, describing each of the particle populations. The 

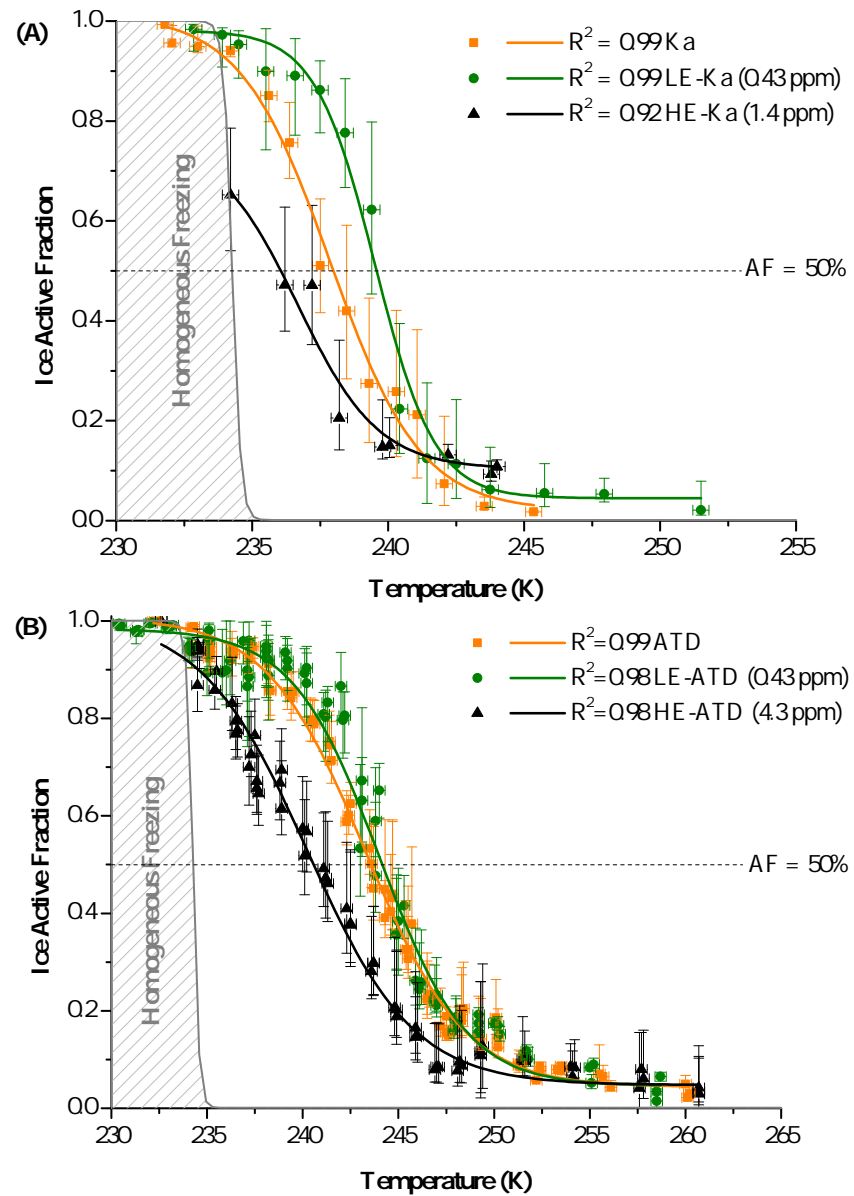

Fig. 8. Ice activated fraction as a function of temperature for immersion mode nucleation of (A) Ka and (B) ATD. Sigmoidal fit equations for curves are presented in Table 4. Homogeneous freezing parameterization is for $10 \mu \mathrm{m}$ water droplets (Earle et al., 2010). Dashed line indicates $50 \%$ of particles frozen. The temperature at which this line intersects the fit lines refers to $T_{50 \%}$ (see text for more details).

LE-ATD and HE-ATD particles show a general suppression of IN activity (based on the fits), however the data exhibit a fair amount of scatter and overlap at $T \leq 245 \mathrm{~K}$ making it difficult to confidently quantify the suppression observed. Overall, the representation of data in Fig. 7 is helpful in clarifying the relative levels of IN activity observed between between the different particle systems that would otherwise not be possible with the cross section of data at $\mathrm{AF}=0.1 \%$ presented in Fig. 5, especially given the onset $\mathrm{RH}_{\mathrm{w}}$ for both LEATD and ATD are within the uncertainty range of the instrument in Fig. 5.

\subsection{Immersion mode ice nucleation}

In Fig. 8 we present the activated ice fraction (AF) from immersion freezing experiments as a function of temperature. The data points have been binned into $0.6 \mathrm{~K}$ tempera-
Table 2. Metrics to compare immersion freezing efficiency of $\mathrm{Ka}$ and ATD particles.

\begin{tabular}{lcc}
\hline Particle Type $\left(\left[\mathrm{O}_{3}\right]\right)$ & $T_{50 \%} \pm 0.4 \mathrm{~K}$ & $T_{\text {onset }} \pm 0.4 \mathrm{~K}$ \\
\hline $\begin{array}{l}\text { Ka }- \text { Low Exposure } \\
\text { (427 ppbv) }\end{array}$ & $239.5(239.9-239.1)$ & $252.0(252.4-251.6)$ \\
Ka - Untreated & $238.0(238.4-237.6)$ & $245.5(245.9-245.1)$ \\
Ka - High Exposure & $236.0(236.4-235.6)$ & $244.0(244.4-243.6)$ \\
$\begin{array}{l}\text { (1.4 ppmv) } \\
\text { ATD - Low Exposure } \\
\text { (429 ppbv) }\end{array}$ & $244.1(244.5-243.7)$ & $260.0(260.4-259.6)$ \\
ATD - Untreated & $243.6(244.0-243.2)$ & $260.5(260.9-260.1)$ \\
$\begin{array}{l}\text { ATD - High Exposure } \\
\text { (4.3 ppmv) }\end{array}$ & $240.5(240.9-240.1)$ & $260.9(261.3-260.5)$ \\
\hline
\end{tabular}

Table 3. Fits for deposition mode ice-active fraction as a function of temperature $(T)$ at $\mathrm{RH}_{\mathrm{W}}=95 \%$ as shown in Fig. 7.

\begin{tabular}{ccc}
\hline $\begin{array}{c}\mathrm{O}_{3} \text { exposure } \\
\text { level }\end{array}$ & $\mathrm{Ka}$ & $\mathrm{ATD}$ \\
\hline None & $\mathrm{AF}=e^{(79.0-0.36 T)}$ & $\mathrm{AF}=e^{(65.3-0.30 T)}$ \\
Low & $\mathrm{AF}=e^{(81.7-0.36 T)}$ & $\mathrm{AF}=e^{(51.8-0.25 T)}$ \\
High & $\mathrm{N} / \mathrm{A}$ & $\mathrm{AF}=e^{(66.4-0.31 T)}$ \\
\hline
\end{tabular}

ture bins, i.e. data point $\pm 0.3 \mathrm{~K}$ of a nominal $T$ to increase clarity and reduce clutter. The sigmoidal fit equations are presented in Table 4. Median freezing temperatures $\left(T_{50 \%}\right)$ and onset temperatures $\left(T_{\text {onset }}\right)$ derived from Fig. $8 \mathrm{a}$ and $\mathrm{b}$ are reported in Table 2. The $T_{50 \%}$ for Ka in this work is $238 \mathrm{~K}$ which is in excellent agreement with the study of Murray et al. (2011) who reported immersion freezing of identical Ka particles (suspensions of 0.05 and $0.1 \%$ by weight) with $T_{50 \%}$ of $238 \mathrm{~K}$ as well. Results from immersion mode studies of different Ka samples (Fluka), show a $T_{50 \%}$ of $241 \mathrm{~K}$ for $800 \mathrm{~nm}$ particles (Lüönd et al., 2010), similar to the mode diameter of the Ka particles used in this study. The higher $T_{50 \%}$ is not surprising as the $\mathrm{Ka}$ from Fluka has been reported to be more active in the immersion freezing mode than the Ka used here (Pinti et al., 2012). The data in Fig. 8a indicate that the LE-Ka particles are more effective immersion IN compared to Ka. There is also a notable reduction in the ice nucleation ability of HE-Ka with a $T_{50 \%}$ of $236 \mathrm{~K}$ compared to $239.5 \mathrm{~K}$ observed for LE-Ka. $T_{\text {onset }}$ for immersion freezing, i.e. the highest temperature at which we can detect ice formation is higher for LE-Ka, consistent with the enhanced IN ability when compared to Ka. Also, the HE-Ka only shows an onset of freezing at temperatures colder than for Ka (see Table 2). However, we note that the AF corresponding to the onset freezing temperature is within the limit of detection $(\mathrm{AF}<0.1)$ of IODE and thus should be treated with caution.

Figure $8 \mathrm{~b}$ shows the immersion freezing results for ATD particles. ATD is more effective as immersion IN with $T_{50 \%}$ of $243.6 \mathrm{~K}$ compared to $238 \mathrm{~K}$ for Ka. The immersion freezing of $300 \mathrm{~nm}$ ATD particles has been reported by 
Table 4. Fits for immersion mode ice-active fraction as a function of temperature (K) as shown in Fig. 8.

\begin{tabular}{ccc}
\hline $\mathrm{O}_{3}$ exposure level & \multicolumn{2}{c}{$\mathrm{Ka}$} \\
\hline None & $\mathrm{AF}=0.012+\left[\frac{0.988}{1+10^{-0.303(238.0-T)}}\right]$ & $\mathrm{AF}=0.044+\left[\frac{0.956}{1+10^{-0.168(243.3-T)}}\right]$ \\
Low & $\mathrm{AF}=0.045+\left[\frac{0.955}{1+10^{-0.395(239.5-T)}}\right]$ & $\mathrm{AF}=0.046+\left[\frac{0.954}{1+10^{-0.191(244.0-T)}}\right]$ \\
High & $\mathrm{AF}=0.103+\left[\frac{0.897}{1+10^{-0.293(236.7-T)}}\right]$ & $\mathrm{AF}=0.048+\left[\frac{0.952}{1+10^{-0.157(240.2-T)}}\right]$ \\
\hline
\end{tabular}

Niedermeier at al. (2010). The $T_{50 \%}$ for their sample was in the homogeneous freezing regime, therefore we compare to their $T_{30 \%}$ of $235 \mathrm{~K}$ to the $T_{30 \%}$ in this work which we found to be $246 \mathrm{~K}$ implying that the particles we use here are more effective at freezing. We suggest two reasons for this. First, the ATD polydisperse sample used here with a particle mode of $400 \mathrm{~nm}$ implies a significant number of 600 and $700 \mathrm{~nm}$ particles. Second, the ATD sample used in our work is a washed sample (as part of the manufacturing process) whereas that of Niedermeier et al. (2010) is unwashed. This could mean significant amounts of soluble material are likely present on their ATD samples. Although polydisperse measurements of ATD in the immersion mode have been previously studied (Connolly et al., 2009), $T_{50 \%}$ were not reported. Similar to HE-Ka, HE-ATD shows a suppression of AF as can be seen from the $T_{50 \%}$ ( $3 \mathrm{~K}$ less than ATD) in Table 2. For ATD we find similar $T_{\text {onset }}$ for HE/LE-ATD and ATD as shown in Table 2 indicating that the aged ATD did not respond to $T_{\text {onset }}$ in the same manner as the exposed $\mathrm{Ka}$ particles. However, at the relatively warm $T_{\text {onset }}$ of ATD, the AF are $\ll 0.1$, which is below the detection limit of IODE and thus we would not be sensitive to any differences in observed IN activity for AF $<0.1$. Fits in Fig. $8 \mathrm{~b}$ are weighed with corresponding error bars. If plotted with the $95 \%$ confidence interval bands (not shown here), the ATD and LEATD datasets exhibit overlap over the measured temperature range. We conclude no significant difference between the AF(T) of ATD and the LE-ATD particles is observed.

The shaded region in Fig. 8 is where homogeneous freezing of $10 \mu \mathrm{m}$ water drops is active (Earle et al., 2010). We cannot attribute any freezing observed here to heterogeneous nucleation. We find that for the HE particles, the homogeneous freezing threshold is reached at lower AF of $65 \%$ and $90 \%$ for HE-Ka and HE-ATD, respectively. However, for the LE and untreated particles, an AF of $100 \%$ is reached before the homogeneous freezing threshold within experimental uncertainty. This behaviour indicates that the ageing inhibited immersion freezing of about 1/3rd of the HE-Ka particles. This is one of the first studies to show an inhibition of ice nucleation explicitly in the immersion regime due to ageing of dust particles from $\mathrm{O}_{3}$ exposure.

\section{Discussion}

\subsection{Comparison of IN ability between deposition and immersion mode ice nucleation}

\subsubsection{Kaolinite}

In the reported temperature range Ka responds uniformly to the ageing process with the LE-Ka yielding better IN than $\mathrm{Ka}$ and $\mathrm{HE}-\mathrm{Ka}$ exhibiting a suppression in AF compared to $\mathrm{Ka}$ for both the immersion and deposition modes as shown in Figs. $7 \mathrm{a}$ and $8 \mathrm{a}$. It is not entirely surprising that the trend observed the deposition nucleation is also mirrored in the immersion freezing mode because for both modes the particle surface is involved in catalysing the stabilisation of an ice germ. However, it is also possible that for a given mode, deposition or immersion, one of the two features, chemical or physical properties, play a more important role in determining ice nucleation. To specifically compare across different IN modes, we choose a convenient $T$ of $\sim 235 \mathrm{~K}$ in Fig. $7 \mathrm{a}$ (deposition mode) and find that there is almost an order of magnitude difference in AF between the LE-Ka, Ka and HE$\mathrm{Ka}$ in that order with LE-Ka being the highest. Comparing $T_{50 \%}$ for the HE-Ka $(\sim 236 \mathrm{~K})$ from Fig. 8a to that of $\mathrm{Ka}$ and LE-Ka, yields a $2 \mathrm{~K}$ and $4 \mathrm{~K}$ higher temperature shift, respectively.

\subsubsection{Arizona Test Dust}

The AF of HE-ATD showed lower IN activity in both immersion and deposition modes. However the suppression observed for HE-ATD occurs to a lesser extent than in HE-Ka. The $\mathrm{O}_{3}$ concentration for HE-ATD (4.3 ppmv) is a factor of 3 more than $\mathrm{HE}-\mathrm{Ka}(1.4 \mathrm{ppmv})$, but the AF in deposition mode of HE-ATD is suppressed by a factor of 3-4 relative to ATD which is less than the suppression by a factor of 10 observed between HE-Ka and Ka (see Fig. 7a). Assuming a linear relationship between deposition mode AF and $\mathrm{O}_{3}$ concentrations used for ageing, ATD would require an $\mathrm{O}_{3}$ exposure of $10 \mathrm{ppm}$ to produce the same suppression in the AF as that observed with HE-Ka. The same comparison can be made for immersion mode freezing. For HE-Ka to show the same suppression as HE-ATD an $\mathrm{O}_{3}$ ageing concentration of $\sim 2.1$ ppmv would be required as opposed to the 1.4 ppmv used for HE-Ka in our experiments. This simple comparison of ice nucleation efficiencies serves to show 

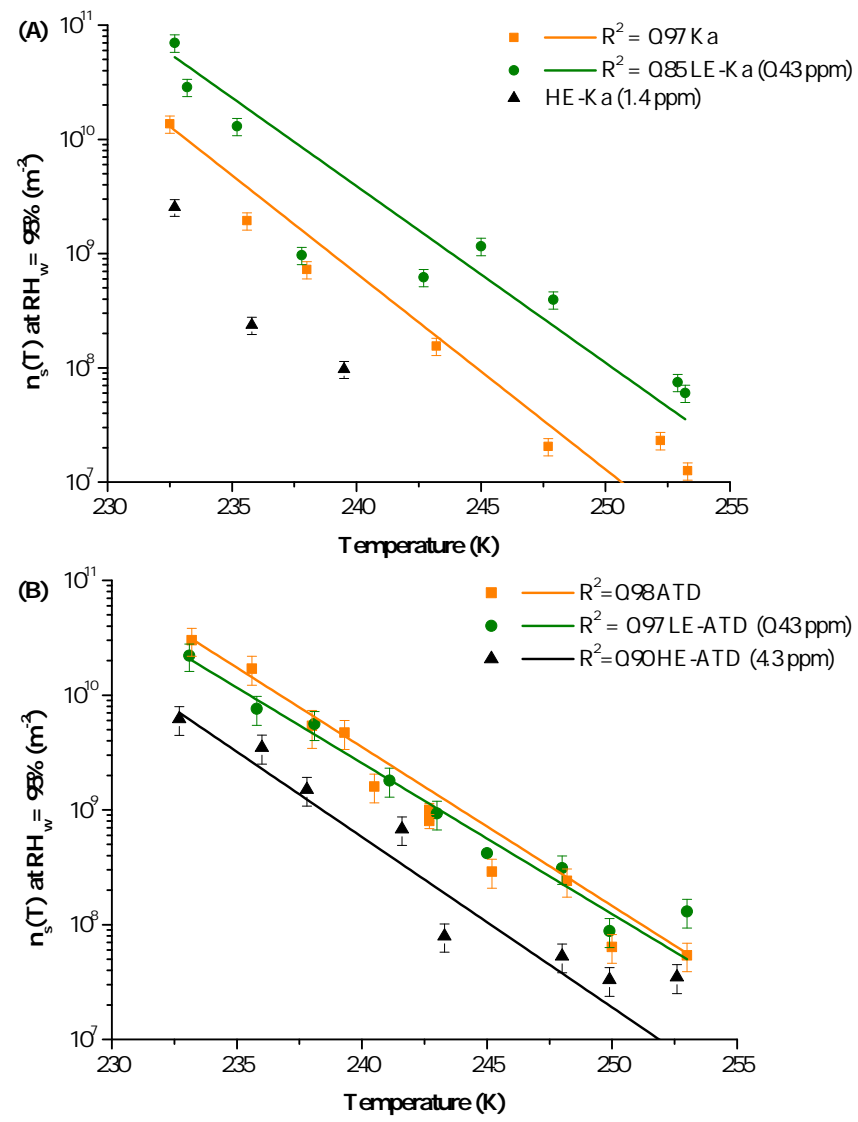

Fig. 9. Ice-active surface site densities as a function of temperature for deposition mode at $\mathrm{RH}_{\mathrm{W}}=95 \%$ (A) Ka and (B) ATD. Exponential fit functions to data are presented in Table 5.

that the two species of MD particles responded differently to the $\mathrm{O}_{3}$ ageing/uptake process as indicated by their uptake coefficients and their ice nucleation efficiency. In addition, MD with varying compositions are expected to show differing IN properties (e.g. Kanji et al., 2008; Archuleta et al., 2005). However, what is initially surprising is that from Fig. $7 \mathrm{~b}$ it appears that LE-ATD and HE-ATD both show suppressed ice nucleation compared to ATD. However, if we quantify ice nucleation by normalising to the surface area of particles rather than to the number, we obtain further clarity into this behaviour.

\subsection{Parameterization of results using ice-active surface site densities as a function of temperature, $n_{\mathrm{s}}(T)$ (singular/deterministic approach)}

This approach assumes that surface sites with specific activation energies are equally distributed over the dust and are responsible for ice formation in a wide range of freezing probabilities as a function of temperature only. $n_{\mathrm{S}}(T)$ is therefore the number of sites on a particle surface that can initiate ice nucleation at a given temperature, assuming that one active site gives rise to a single ice crystal. Studies have shown
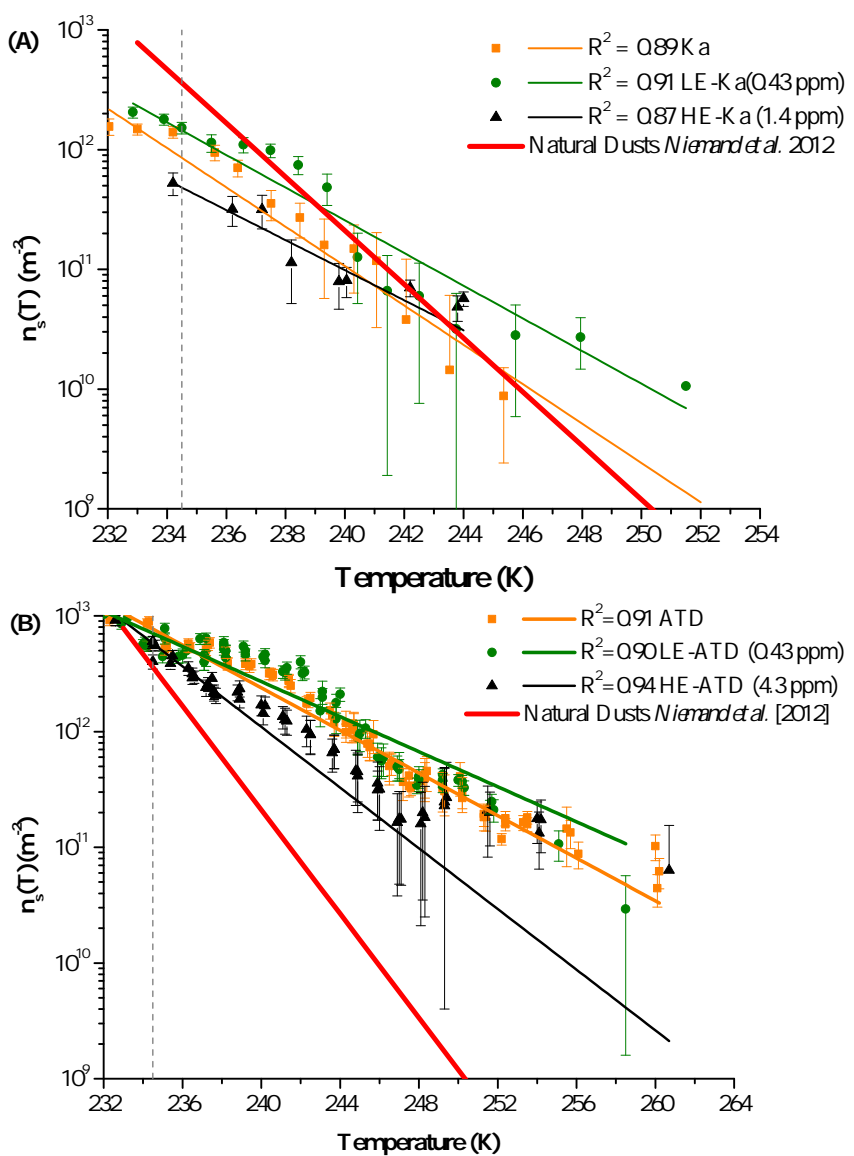

Fig. 10. Ice-active surface site densities as a function of temperature for immersion mode freezing of (A) Ka and (B) ATD. Exponential fit functions to data are given in Table 6. Dashed line: homogeneous freezing temperature for $10 \mu \mathrm{m}$ water droplets (Earle et al., 2010). Fit function for natural dusts from Niemand et al. (2012): $n_{\mathrm{S}}(T)=$ $\exp (-0.517 T+8.934)\left(\mathrm{m}^{-2}\right)$.

the dependence of ice nucleation on particle surface area in both immersion (Murray et al., 2012 and references therein) and deposition (e.g. Kanji and Abbatt, 2010; Wheeler and Bertram, 2012). In this parameterization time dependence is not taken into account similar to the work of Connolly et al. (2009) and Niemand et al. (2012). Justification for using the $n_{\mathrm{S}}(T)$ parameterization comes from a number of reasons. In a time dependence study of immersion freezing of Ka (Fluka) particles (Welti et al., 2012), the frozen fraction was observed to depend on time for the first $10 \mathrm{~s}$, but for 11$22 \mathrm{~s}$, a time dependency was not observed. Using the bestfit time dependent parameters and a log-normal aerosol distribution, model runs were used to extend the time dependent fits to $30 \mathrm{~min}$ to represent glaciation in a cloud. It was found that an order of magnitude increase in time would be required to produce the same frozen fraction resulting from a cooling of $1 \mathrm{~K}$. i.e. a small change in supercooling will cause a much larger change in frozen fraction than will time, concluding that temperature is a much stronger predictor of 
frozen fraction than time (Welti et al., 2012). For deposition mode, the work of Wheeler and Bertram (2012) showed that the deterministic approach produced the best fit to their iceactive fraction dependency on onset $\mathrm{RH}$, contrary to what one would expect from classical nucleation theory. Lastly, in the work of Kanji and Abbatt (2006), a simple test was conducted where maintaining the $\mathrm{RH}_{\mathrm{i}}$ roughly $2 \%$ below the onset $\mathrm{RH}_{\text {ice }}$ (determined apriori) for Saharan dust particles at approximately $233 \mathrm{~K}$ for 20 min or longer did not result in ice nucleation, however increasing $\mathrm{RH}_{\mathrm{i}}$ to onset conditions resulted in ice formation within less than $0.4 \mathrm{~s}$. However, a recent study by Rigg et al. (2013) argues that the $n_{\mathrm{s}}(T)$ parameterization does not yield a physical relationship of particle properties and ice-active sites and suggest a water activity based description of immersion freezing (Knopf and Alpert, 2013). In addition, recent cloud resolving modelling study suggests the necessity of a time dependent ice formation process for stable, long-lived clouds (Westbrook and Illingworth, 2013). This is contrasted by the sensitivity of Ervens and Feingold (2013) who showed that ice nucleation is much less sensitive to time compared to temperature, particle size and contact angle. To facilitate comparison with previous studies, we analyze our immersion freezing data using a singular/deterministic approach. $n_{\mathrm{S}}(T)$ serves as a convenient way to implement laboratory results into climate models and to extrapolate to atmospheric ice crystal concentrations as is discussed in Sect. 5.

To parameterize our results, we determine $n_{\mathrm{s}}(T)$, at a fixed RH for both ice nucleation modes. This can be done if we assume that the particles within a sample are of uniform composition and that $n_{\mathrm{S}}(T)$ does not change with particle size. In the following, $n_{\mathrm{s}}(T)$ is calculated as described in Hoose and Möhler (2012) for both immersion and deposition mode data that are shown in Figs. 7 and 8.

$n_{\mathrm{S}}(T)=\frac{-1}{\mathrm{SA}} \ln (1-\mathrm{AF})$

$n_{\mathrm{S}}(T) \approx \frac{\mathrm{AF}}{\mathrm{SA}}=\frac{N_{\mathrm{IN}}}{\mathrm{SA}_{\mathrm{tot}}}$,

where SA $\left(\mathrm{m}^{2}\right)$ is the geometric surface area of a particle, $\mathrm{AF}$ is the activated ice fraction, $N_{\mathrm{IN}}$ is the ice crystal concentration $\left(\# \mathrm{~cm}^{-3}\right)$ and $\mathrm{SA}_{\text {tot }}\left(\mathrm{m}^{-2} \mathrm{~cm}^{-3}\right)$ is the surface area concentration of the polydisperse sample. The approximation (Eq. 4) is only valid for AF $<0.1$ and therefore we use the approximation to only determine $n_{\mathrm{S}}(T)$ for the deposition mode data which satisfies this criterion. Since the immersion mode data span AF $>0.1$, we use Eq. (3) with the particle mode size of each sample to determine the SA, assuming spherical particles. The mode size of the dust samples does not change over the course of sampling from the aerosol tank, thus it is a reasonable assumption. In Figs. 9 and 10 we present the $n_{\mathrm{s}}(T)$ for deposition mode and immersion mode ice nucleation, respectively.
The results for Ka in Fig. 9a for deposition mode confirm those presented in Fig. 7a. The $n_{\mathrm{S}}$ of LE-Ka are 1 and 2 orders of magnitude higher than Ka and HE-Ka, respectively. The difference in $n_{\mathrm{S}}$ between the HE-Ka and LE-Ka in the temperature range studied implies that the increased exposure of dust to $\mathrm{O}_{3}$ in the atmosphere could have an impact on the deposition mode ice nucleation properties. $n_{\mathrm{s}}(T)$ for Ka in the immersion mode presented in Fig. 10a show that $n_{\mathrm{S}}$ of LE-Ka is a factor of 5 more than Ka at warmer $T \sim 250 \mathrm{~K}$. At colder $T$, the $n_{\mathrm{s}}$ merge as the homogeneous freezing limit is approached with the difference being less than a factor of 2 at $233 \mathrm{~K}$. Based on the fits, the $n_{\mathrm{s}}$ of HE-Ka does not differ significantly from that of Ka. Compared to LE-Ka, the $n_{\mathrm{S}}$ for HE-Ka is smaller by a factor of $\sim 4$ implying that the $\mathrm{O}_{3}$ ageing had a smaller impact in the immersion mode compared to deposition mode where the HE-Ka are $\sim 100$ times less active than the LE-Ka.

In Fig. 10b, when we account for $n_{\mathrm{S}}(T)$ of ATD in the deposition mode, we find that the IN activity of LE-ATD is similar to ATD while the suppression of IN activity is now apparent for HE-ATD, which otherwise showed some scatter in Fig. 7b. This is a good illustration of the importance of quantifying the ice nucleation activity of particles using surface area. $n_{\mathrm{S}}(T)$ for ATD in the immersion mode presented in Fig. 10b corroborate the observations from the AF in Fig. 8b. If $n_{\mathrm{s}}$ fits of LE-ATD and ATD are plotted with $95 \%$ confidence interval bands (not shown here), overlap over the entire temperature range is found. There is approximately an order of magnitude difference in $n_{\mathrm{S}}$ between HE-ATD and ATD at warmer $T \sim 256 \mathrm{~K}$. All $n_{\mathrm{s}}$ curves merge at colder temperature suggesting that the changes due to $\mathrm{O}_{3}$ ageing is playing a role at warmer temperatures, but as the homogenous freezing limit is approached, the type of IN matters less and temperature is the primary determinant for freezing. This is indicated by the steep homogeneous freezing curve of pure water drops at $\sim 234 \mathrm{~K}$ and frozen fraction of $\sim 1$ as is shown in Fig. 8a and b. The merging of the $n_{\mathrm{s}}$ fits at homogenous freezing temperature is also observed for the LE-Ka and Ka particles, however not for the HE-Ka (see Fig. 10a). This indicates that a subset of the HE-Ka were completely deactivated and unable to induce ice formation even at the coldest heterogeneous freezing temperature. The same behaviour was not observed with HE-ATD despite the higher $\mathrm{O}_{3}$ concentration of $4.3 \mathrm{ppmv}$ used compared to only $1.4 \mathrm{ppmv}$ for HE-Ka supporting our discussion (Sect. 4.1.2) that higher $\mathrm{O}_{3}$ concentrations would be required for ATD to show the same suppression as Ka. Confidence in the suppression of HE-Ka being due to the $\mathrm{O}_{3}$ ageing comes from the fact that $\mathrm{Ka}$ and LE-Ka display $100 \%$ activation (within experimental uncertainty) at $T \sim 234 \mathrm{~K}$ as shown in Fig. $8 \mathrm{a}$.

Lastly, the $n_{\mathrm{s}}$ for Ka and ATD in deposition mode at for example, $T=235 \mathrm{~K}$, are $\sim 2.5$ orders of magnitude lower than that observed for immersion freezing, implying that the MD particles used in the current work have a surface that is more active in immersion mode ice nucleation. In other 
words only a small fraction of particles out of a sample population are active to ice nucleation in the deposition mode for $\mathrm{RH}_{\mathrm{w}}=95 \%$, as is often indicated by the lower AF observed in deposition mode studies.

\subsection{Effect of $\mathrm{O}_{3}$ ageing on the ice nucleation of $\mathrm{Ka}$ and ATD particles}

\subsubsection{Effect of low $\mathrm{O}_{3}$ exposure}

Enhancement of the IN ability of $\mathrm{Ka}$ exposed to $\mathrm{O}_{3}$ is reasonable given that $\mathrm{O}_{3}$ is a powerful oxidant and is known to react with mineral and oxide surfaces making them more hydrophilic. Increased water vapour uptake observed at $\mathrm{RH}_{\mathrm{w}}=$ $90 \%$ onto $\mathrm{O}_{3}$ treated alumina compared to untreated alumina has been reported to occur in association with reactively formed surface species appearing in the form $\mathrm{M}=\mathrm{O}$ (Roscoe and Abbatt, 2005). Mechanisms whereby an $\mathrm{O}$ atom becomes incorporated into MD surfaces upon $\mathrm{O}_{3}$ exposure have been proposed in a number of studies (Usher et al., 2003a and references therein). Such surface oxide species can play a role in stabilising a water cluster through dipole intermolecular forces with the $\mathrm{H}_{2} \mathrm{O}$ molecule thus lowering the energy barrier of ice germ formation (Pruppacher and Klett, 1997). The enhanced ice nucleation activity of LE-Ka observed here could be due to water adsorption on the alumina rich ( $40 \%$ by mass) particle surface given that water vapour molecules play a key role in the deposition ice nucleation. For immersion mode, the particles instantaneously activate to liquid droplets upon entering IMCA therefore water vapour adsorption is not relevant. The smaller enhancement of LE$\mathrm{Ka}$ in the immersion mode (Fig. 10a) relative to deposition nucleation is therefore expected and could be due to a surface oxide $(\mathrm{M}=\mathrm{O})$ species resulting from $\mathrm{O}_{3}$ exposure providing active sites for stabilisation of liquid water clusters or making the Ka surface more hydrophilic.

Compared to ATD, LE-ATD did not show a detectable change in ice formation for both deposition and immersion modes. Given the BET surface area of ATD is $50 \%$ that of $\mathrm{Ka}$ a smaller surface area is altered due to heterogeneous oxidation of $\mathrm{O}_{3}$. It is possible that the ice nucleation experiments performed here are not impacted by or not sensitive enough to detect the change occurring on the ATD surface due to $\mathrm{O}_{3}$ exposure. On the other hand, it is possible that there is no change occurring at the surface of the ATD. The magnitude of the surface ozone coverage of ATD (see Table 1 and Sect. 3.1) suggests there is some catalytic activity. An $\mathrm{O}_{2}$ molecule is likely released per site regenerating the surface sites with little to no change of the surface at the $\mathrm{O}_{3}$ concentrations used for the LE experiments (Cwiertny et al., 2008).

\subsubsection{Effect of high $\mathrm{O}_{3}$ exposure}

At first glance the suppression observed in both Ka and ATD is counter intuitive since one could expect that a higher $\mathrm{O}_{3}$ exposure should result in larger enhancement in AF than the low $\mathrm{O}_{3}$ exposure experiments, assuming a linear relation. However, in context of $\mathrm{O}_{3}$ uptake measurements on MD reported in the literature (Hanisch and Crowley, 2003), we suggest an explanation for the observed suppression of IN ability. Hanish and Crowley (2003) reported that $\mathrm{O}_{3}$ can bind to MD surfaces in both reactive and unreactive configurations and that non-reactively bound $\mathrm{O}_{3}$ will result in blocking reactive $\mathrm{O}_{3}$ sites. This is thought to particularly occur at higher $\mathrm{O}_{3}$ concentrations such as those used for our HE experiments. We propose that blocked sites are unable to catalyse water adsorption as occurs in the LE experiments (see Sect. 4.3.1). In addition, competitive adsorption of $\mathrm{O}_{3}$ and water vapour could also be occurring. If $\mathrm{O}_{3}$ adsorbs to surface sites and blocks water adsorption, the effective available surface area and thus $n_{\mathrm{s}}$ will decrease. This is likely to occur since $\mathrm{O}_{3}$ was present in the sample layer during the ice nucleation experiments. The weaker suppression exhibited by HE-ATD is expected due to the lower number of surface sites available for heterogeneous uptake of $\mathrm{O}_{3}$ indicated by the lower BET surface area.

For immersion freezing HE-ATD showed a larger suppression in $n_{\mathrm{S}}$ than HE-Ka. A reason could be due blocked active sites on the surface of ATD as discussed above. In particular, if the condensation of water onto the HE-Ka particles prior to freezing, results in the dissociation of the $\mathrm{O}_{3}$ from the blocked surface sites, whereas the same is not occurring with ATD either due to the different surface composition or due to the higher $\mathrm{O}_{3}$ concentration for the HE-ATD experiments.

\subsection{Limitations}

The surrogates of atmospheric MD used here are not replicates of the atmospheric dust. Despite the minimal processing involved in producing the Ka particles used here, it is a single component clay. On the other hand, ATD is representative of a natural dust composition (complex mixture), but undergoes significant milling and drying in its production process which likely results particles being altered as an IN compared to natural desert dusts. Nevertheless, this work shows that there is an effect of $\mathrm{O}_{3}$ exposure on the dust particles and future studies can focus on natural desert dust particles or other clay minerals such as illite.

As discussed at the end of Sect. 3.1, the typical $\mathrm{O}_{3}$ concentrations in the troposphere are an order of magnitude lower than those used in the current work for our low exposure studies. This could result in lower surface coverage in the atmosphere and thus the extent to which IN properties are altered could vary from what we present here. However, this work shows that there is an $\mathrm{O}_{3}$ concentration effect on the 
IN properties and it would be necessary to conduct studies at lower concentrations.

Lastly, we use the spherical assumption for geometric surface area to be consistent when comparing the outcome of IN concentrations from the $n_{\mathrm{s}}(T)$ parameterizations to those from the field studies (presented in Sect. 5) because surface areas estimated from the field studies are also based on geometrical surface areas. This also ensures consistency when comparing our $n_{\mathrm{s}}(T)$ to previous studies. The BET surface area may over estimate the surface available to a water molecule adsorbing to the surface of a MD particle because of the partly hydrophobic nature of MD particles, thus one can expect that a smaller area is available to water molecules than the surface occupied by $\mathrm{N}_{2}$ for BET measurements (Zettlemoyer et al., 1961). Additionally, we assume that the particle composition across different sizes is uniform, which is not true for ATD submicron particle composition compared to the bulk (Vlasenko et al., 2005; Knopf and Koop, 2006). However we note that the particles used here are all in the submicron size range.

\subsection{Comparison to previous work}

This is one of the first studies to show an inhibition of ice nucleation explicitly in the immersion regime due to ageing of dust particles from $\mathrm{O}_{3}$ exposure. There has been one previous study that investigated the influence on ice nucleation of ageing montmorillonite at $200 \mathrm{ppbv} \mathrm{O}_{3}$ for $233<T<258 \mathrm{~K}$ (Salam et al., 2008). In the study, a CFDC was used to detect deposition mode ice nucleation and results reported for $\mathrm{AF}$ at $\mathrm{RH}_{\mathrm{w}}=90 \%$ showed no difference in IN activity between $\mathrm{O}_{3}$ aged and untreated montmorillonite particles. This is contrary to what we observe in the deposition mode for aged Ka. Reasons for this could be numerous. First, montmorillonite will exhibit dissimilar surface composition and active site distributions will likely differ compared to Ka or ATD. Second, one concentration of $\mathrm{O}_{3}$ (200 ppbv) was applied in the Salam et al. (2008) study, which is less than half the concentration used in the LE here. Third, ageing times were significantly different, $70 \mathrm{~h}$ in the Salam et al. (2008) study and $\sim 2 \mathrm{~h}$ in the current work. To date there are no additional studies that have investigated the ice nucleation properties of dust aged with $\mathrm{O}_{3}$. A number of studies discussed in the literature have looked at IN effects from ageing through condensing inorganic or organic coatings onto MD particles and have found a reduced efficiency of ice nucleation in particular for deposition mode (see Sect. 1).

The parameterization for $n_{\mathrm{s}}(T)$ from the work of Niemand et al. (2012) derived from fitting collectively the immersion mode freezing $n_{\mathrm{S}}(T)$ for natural untreated dust samples including Asian Dust, Canary Island Dust, Israeli Dust and Saharan Dust is plotted in Fig. 10. Their parameterization fit is based on data obtained in the $T$ range 258 to $238 \mathrm{~K}$. We plot this parameterization and extrapolate it to $232 \mathrm{~K}$ to compare to the $n_{\mathrm{s}}$ derived in this work. The natural dusts have $n_{\mathrm{s}}$ that are comparable to that of Ka for $T>240 \mathrm{~K}$. This parameterization suggests that the Ka from Clay Mineral Society used may have an ice nucleation activity that is closer to that observed for natural dusts, contrary to what is observed in Fig. 10b where the natural dust $n_{\mathrm{S}}$ at $T>235 \mathrm{~K}$ are significantly lower than that of ATD. What is striking is that the natural dust fit is significantly lower than the already suppressed $n_{\mathrm{S}}$ of HE-ATD lending support to the active IN nature of ATD compared to other MD species (Murray et al., 2012) attributed to the manufacturing process of ATD.

\section{Atmospheric implications}

In this work we observe $\mathrm{O}_{3}$ loss to both $\mathrm{Ka}$ and ATD surfaces implying that $\mathrm{MD}$ is a sink for $\mathrm{O}_{3}$. It has been reported that uptake coefficients of at least $10^{-5}$ are required for the heterogeneous reaction of $\mathrm{O}_{3}$ to be considered an important loss pathway in the atmosphere (Dentener et al., 1996). In the current work we observe such losses on both Ka and ATD (Table 1) implying that such particles will be a significant sink in the atmosphere.

The $\mathrm{O}_{3}$ ageing of MD particles presented in this work has been shown to alter heterogeneous ice nucleation properties of $\mathrm{Ka}$ and ATD. The $\mathrm{O}_{3}$ concentrations used in this work are higher than typical atmospheric concentrations, except in some cases discussed at the end of Sect. 3.1. There is an enhancement observed in the ice nucleation of Ka due to moderate ageing with $\mathrm{O}_{3}$. Such an increase in heterogeneous freezing efficiency could affect the onset of homogeneous freezing in the atmosphere in the presence of efficient IN as has been shown using box model simulations (Spichtinger and Cziczo, 2010).

We use the derived parameterizations for Ka to demonstrate a simple example of the usefulness of the $n_{\mathrm{S}}(T)$ parameterization. We choose Ka since it exhibits a closer match to natural desert dust IN activity. The following assessment is relevant for regions of the troposphere where the updraft velocities are high enough, for example the upper tropical troposphere (Lohmann and Feichter, 2005) such that ice formation is largely dependent on temperature. To make the connection to the atmosphere, we estimate the potential concentration of atmospheric IN using $n_{\mathrm{S}}(T)$ for Ka and LE-KA for immersion mode from Table 6 at $248 \mathrm{~K}$ to be $3.6 \times 10^{9}$ sites $^{-2}$ and $6.0 \times 10^{9}$ sites $\mathrm{m}^{-2}$, respectively. Estimates of the surface area concentration of potential aerosol particles that can nucleate ice in the atmosphere are calculated using the range in Murray et al. (2012) for dust, 0.150 particles $\mathrm{cm}^{-3}$. Assuming $d=1 \mu \mathrm{m}$ and spherical particles, the surface area available for potential ice nucleation is $3.1 \times 10^{-13}$ to $1.6 \times 10^{-10} \mathrm{~m}^{-2} \mathrm{~cm}^{-3}$, respectively. The potential IN concentrations can then be estimated according to

$$
\begin{aligned}
{[\mathrm{IN}]_{248 \mathrm{~K}}\left(\# \mathrm{~cm}^{-3}\right) } & =n_{\mathrm{S}}(248 \mathrm{~K})\left(\text { sites }^{-2}\right) \\
& \times \mathrm{SA}_{\text {tot }}\left(\mathrm{m}^{-2} \mathrm{~cm}^{-3}\right) .
\end{aligned}
$$


Table 5. Fits for deposition mode ice-active surface site density $\left(\mathrm{m}^{-2}\right)$ as a function of temperature $(\mathrm{K})$ at $\mathrm{RH}_{\mathrm{W}}=95 \%$ as shown in Fig. 9.

\begin{tabular}{ccc}
\hline $\begin{array}{c}\mathrm{O}_{3} \text { exposure } \\
\text { level }\end{array}$ & $\mathrm{Ka}$ & $\mathrm{ATD}$ \\
\hline None & $n_{\mathrm{S}}=e^{(115.2-0.3952 T)}$ & $n_{\mathrm{S}}=e^{(98.44-0.3186 T)}$ \\
Low & $n_{\mathrm{S}}=e^{(107.5-0.3561 T)}$ & $n_{\mathrm{S}}=e^{(94.34-0.3028 T)}$ \\
High & N/A & $n_{\mathrm{S}}=e^{(102.21-0.3418 T)}$ \\
\hline
\end{tabular}

We find that the IN concentrations would be on the order of $10^{-3}-10^{-1} \mathrm{~cm}^{-3}$ and $10^{-2}-10 \mathrm{~cm}^{-3}$ for particles that have IN properties similar to $\mathrm{Ka}$ and $\mathrm{LE}-\mathrm{Ka}$ in the immersion mode, respectively. The range of IN concentrations derived from the Ka parameterization here agree extremely well with the potential atmospheric IN concentrations reported in Murray et al. (2012) of $10^{-4}-10 \mathrm{~cm}^{-3}$ for natural desert dusts.

To demonstrate the relation of this work to the atmosphere, we refer to the CRYSTAL-FACE campaign (DeMott et al., $2003 \mathrm{~b}$ ), which report peak IN concentrations of $1-2 \mathrm{~cm}^{-3}$ in a dust storm using an IN counter in the deposition mode at $\mathrm{RH}_{\mathrm{W}}=86 \%$ and $T=236 \mathrm{~K}$. The surface area present during the dust storm estimated from the data presented in the paper is $3 \times 10^{-6} \mathrm{~cm}^{2} \mathrm{~cm}^{-3}$, which is similar to the surface area of $1.6 \times 10^{-6} \mathrm{~cm}^{2} \mathrm{~cm}^{-3}$ reported for another Saharan dust storm event (de Reus et al., 2000). The $n_{\mathrm{s}}(236 \mathrm{~K})$ from our deposition mode parameterizations of Ka (Table 5), we get $3.3 \times 10^{9}$ sites $\mathrm{m}^{-2}$. Using Eq. (5) we predict an IN concentration of $1 \mathrm{~cm}^{-3}$. This is in remarkably good agreement for the extrapolation of a laboratory study to a field measurement given instrument uncertainties. We also note that during CRYSTAL-FACE, MD residuals from ice crystals were found to be bare and not internally mixed with sulfate or organics. We note that the conditions of the field study guide our choice of the applied parameterization for this example. For instance, using the parameterizations for aged Ka or ATD would not yield agreement between measured and predicted values.

\section{Conclusions}

The immersion and deposition ice nucleation properties for $233<T<264 \mathrm{~K}$ of two mineral dust particle types, kaolinite (KGa-1b) and Arizona Test Dust, aged with $\mathrm{O}_{3}$ (0.43 ppmv for Ka and ATD, 1.4 ppmv for Ka and 4.3 ppmv for ATD) are presented. Uptake coefficients $(\gamma)$ determined for the above ageing experiments were found to be of the order of $10^{-5}$ and $10^{-4}$ for kaolinite and Arizona Test Dust, respectively which are in agreement with previous values reported in the literature. We present parameterizations of ice-active fractions and surface densities as a function of temperature for both ice nucleation modes that can be used for comparison to other studies and for implementation in ice nucleation modelling
Table 6. Fits for immersion mode ice-active surface site density $\left(\mathrm{m}^{-2}\right)$ as a function of temperature $(\mathrm{K})$ as shown in Fig. 10.

\begin{tabular}{ccc}
\hline O $_{3}$ exposure level & Ka & ATD \\
\hline None & $n_{\mathrm{S}}=e^{(116.3-0.38 T)}$ & $n_{\mathrm{S}}=e^{(79.4-0.21 T)}$ \\
Low & $n_{\mathrm{S}}=e^{(101.7-0.31 T)}$ & $n_{\mathrm{S}}=e^{(70.5-0.17 T)}$ \\
High & $n_{\mathrm{S}}=e^{(94.7-0.29 T)}$ & $n_{\mathrm{S}}=e^{(100.2-0.30 T)}$ \\
\hline
\end{tabular}

work. This is the first study to show the enhancement of IN activity of mineral dust particles due to chemical ageing for both deposition and immersion mode ice nucleation.

We observe non-uniform and non-linear responses in ice nucleation to ozone ageing of kaolinite and Arizona Test Dust particles for low and high effective ozone ageing times in both immersion and deposition mode ice nucleation. For ageing times of $\sim 130 \mathrm{~min}$ and $\mathrm{O}_{3}$ concentrations of $\sim 430 \mathrm{ppbv}$, equivalent to particles exposed to typical tropospheric background ozone concentrations of $45 \mathrm{ppbv}$ for 1 day, we found that aged kaolinite particles showed enhanced ice nucleation activity compared to untreated kaolinite in the deposition and immersion mode in the temperature range studied here $(264-233 \mathrm{~K})$. For the same level of $\mathrm{O}_{3}$ ageing Arizona Test Dust showed a small, quantitatively insignificant enhancement of ice nucleation activity (based on $n_{\mathrm{s}}$ ) for both deposition and immersion ice nucleation. Compared to untreated kaolinite, particles aged for $\sim 130 \mathrm{~min}$ at 1.4 ppmv showed a lower ice nucleation activity in the temperature range $232-240 \mathrm{~K}$ in the deposition mode. For immersion mode only a small suppression of ice-active surface sites was found for the entire temperature range presented. Compared to untreated Arizona Test Dust, particles aged for the same time at 4.3 ppmv $_{3}$, showed a significantly lower ice nucleation in the deposition mode across the temperature range studied. In the immersion mode, the same particles were found to have up to an order of magnitude lower ice-active surface sites in the investigated temperature range.

From the ice-active surface site density parameterization, we show that Arizona Test Dust has significantly higher ice nucleation activity compared to kaolinite and natural desert dusts. The kaolinite parameterizations were applied for prediction of ice nuclei concentrations measured in the atmosphere. Good agreement with previous values reported from field measurements of ice nuclei concentrations conducted inside dust plumes was found. We also suggest that the kaolinite sample used here (KGa-1b) from Clay Mineral Society is a better surrogate for natural desert dusts than Arizona Test Dust. Using ice-active site densities is a convenient way of comparing ice nucleation data across different modes, sample types and instruments; it should be noted that particle size effects (due to non-uniform composition across varying particle sizes) and time can still transcend this representation, in particular for particles with diameters less than $100 \mathrm{~nm}$ where the probability occurrence of an ice-active site is very 
low (Kanji and Abbatt, 2010). To extrapolate these results to regions in the atmosphere where ice nucleation results from small cooling rates, it would be beneficial to include a time dependent parameterization based on classical nucleation theory (Knopf and Alpert, 2013; e.g. Welti et al., 2012; Murray et al., 2011; Rigg et al., 2013).

In our work deposition mode was significantly affected by the ageing experiments, thus similar studies would be desirable at temperatures relevant to the cirrus regime $(T<233 \mathrm{~K}$ ) where deposition mode is more important. In order to better understand the processes of ageing and their effects on ice nucleation, similar experiments with other trace gases, such as $\mathrm{NO}_{2}$ and $\mathrm{SO}_{2}$, should be performed with a variety of atmospherically relevant mineral particles and also with monodisperse particle populations. Systematic investigations of the response of ice nuclei varying ageing gas concentrations are desirable to explore the potential mechanisms of enhancing or suppressing the ice nucleation efficiency of mineral dusts.

Acknowledgements. The authors would like to acknowledge Hannes Wydler for technician support, Jon Abbatt for helpful discussions and funding from the Swiss National Science Foundation (SNSF) project contract number 200021_127275, "Laboratory and Field Studies of Ice Nucleation: Natural and Anthropogenic Effects".

Edited by: D. Knopf

\section{References}

Abbatt, J. P. D.: Interactions of atmospheric trace gases with ice surfaces: Adsorption and reaction, Chem. Rev., 103, 4783-4800, doi:10.1021/cr0206418, 2003.

Alpert, P. A., Aller, J. Y., and Knopf, D. A.: Ice nucleation from aqueous $\mathrm{NaCl}$ droplets with and without marine diatoms, Atmos. Chem. Phys., 11, 5539-5555, doi:10.5194/acp-11-55392011, 2011.

Andreae, M. O. and Rosenfeld, D.: Aerosol-cloudprecipitation interactions. Part 1. The nature and sources of cloud-active aerosols, Earth-Sci. Rev., 89, 13-41, doi:10.1016/j.earscirev.2008.03.001, 2008.

Archuleta, C. M., DeMott, P. J., and Kreidenweis, S. M.: Ice nucleation by surrogates for atmospheric mineral dust and mineral dust/sulfate particles at cirrus temperatures, Atmos. Chem. Phys., 5, 2617-2634, doi:10.5194/acp-5-2617-2005, 2005.

Baustian, K. J., Cziczo, D. J., Wise, M. E., Pratt, K. A., Kulkarni, G., Hallar, A. G., and Tolbert, M. A.: Importance of aerosol composition, mixing state, and morphology for heterogeneous ice nucleation: A combined field and laboratory approach, J. Geophys. Res.-Atmos., 117, D06217, doi:10.1029/2011jd016784, 2012.

Cantrell, W. and Heymsfield, A.: Production of ice in tropospheric clouds - A review, B. Am. Meteorol. Soc., 86, 795-807, doi:10.1175/bams-86-6-795, 2005.

Chang, R. Y. W., Sullivan, R. C., and Abbatt, J. P. D.: Initial uptake of ozone on Saharan dust at atmospheric relative humidities, Geophys. Res. Lett., 32, L14815, doi:10.1029/2005g1023317, 2005.
Chou, C., Stetzer, O., Weingartner, E., Jurányi, Z., Kanji, Z. A., and Lohmann, U.: Ice nuclei properties within a Saharan dust event at the Jungfraujoch in the Swiss Alps, Atmos. Chem. Phys., 11, 4725-4738, doi:10.5194/acp-11-4725-2011, 2011.

Chou, C., Kanji, Z. A., Stetzer, O., Tritscher, T., Chirico, R., Heringa, M. F., Weingartner, E., Prévôt, A. S. H., Baltensperger, U., and Lohmann, U.: Effect of photochemical ageing on the ice nucleation properties of diesel and wood burning particles, Atmos. Chem. Phys., 13, 761-772, doi:10.5194/acp-13-761-2013, 2013.

Colarco, P. R., Toon, O. B., Reid, J. S., Livingston, J. M., Russell, P. B., Redemann, J., Schmid, B., Maring, H. B., Savoie, D., Welton, E. J., Campbell, J. R., Holben, B. N., and Levy, R.: Saharan dust transport to the Caribbean during PRIDE: 2. Transport, vertical profiles, and deposition in simulations of in situ and remote sensing observations, J. Geophys. Res.-Atmos., 108, 8590, doi:10.1029/2002jd002659, 2003.

Connolly, P. J., Möhler, O., Field, P. R., Saathoff, H., Burgess, R., Choularton, T., and Gallagher, M.: Studies of heterogeneous freezing by three different desert dust samples, Atmos. Chem. Phys., 9, 2805-2824, doi:10.5194/acp-9-2805-2009, 2009.

Cwiertny, D. M., Young, M. A., and Grassian, V. H.: Chemistry and photochemistry of mineral dust aerosol, in: Annual Review of Physical Chemistry, Annual Review of Physical Chemistry, Annual Reviews, Palo Alto, 27-51, 2008.

Cziczo, D. J., Murphy, D. M., Hudson, P. K., and Thomson, D. S.: Single particle measurements of the chemical composition of cirrus ice residue during CRYSTAL-FACE, J. Geophys. Res.Atmos., 109, D04201, doi:10.1029/2003JD004032, 2004.

Cziczo, D. J., Froyd, K. D., Gallavardin, S. J., Moehler, O., Benz, S., Saathoff, H., and Murphy, D. M.: Deactivation of ice nuclei due to atmospherically relevant surface coatings, Environ. Res. Lett. , 4, 044013, doi:10.1088/1748-9326/4/4/044013, 2009.

DeCarlo, P. F., Slowik, J. G., Worsnop, D. R., Davidovits, P., and Jimenez, J. L.: Particle morphology and density characterization by combined mobility and aerodynamic diameter measurements. Part 1: Theory, Aerosol Sci. Technol., 38, 1185-1205, doi:10.1080/027868290903907, 2004.

DeMott, P. J., Cziczo, D. J., Prenni, A. J., Murphy, D. M., Kreidenweis, S. M., Thomson, D. S., Borys, R., and Rogers, D. C.: Measurements of the concentration and composition of nuclei for cirrus formation, P. Natl. Acad. Sci. USA, 100, 14655-14660, 2003a.

DeMott, P. J., Sassen, K., Poellot, M. R., Baumgardner, D., Rogers, D. C., Brooks, S. D., Prenni, A. J., and Kreidenweis, S. M.: African dust aerosols as atmospheric ice nuclei, Geophys. Res. Lett., 30, 1732, doi:10.1029/2003GL017410, 2003 b.

DeMott, P. J., Petters, M. D., Prenni, A. J., Carrico, C. M., Kreidenweis, S. M., Collett, J. L., and Moosmuller, H.: Ice nucleation behavior of biomass combustion particles at cirrus temperatures, J. Geophys. Res.-Atmos., 114, D16205, doi:10.1029/2009jd012036, 2009.

DeMott, P. J., Prenni, A. J., Liu, X., Kreidenweis, S. M., Petters, M. D., Twohy, C. H., Richardson, M. S., Eidhammer, T., and Rogers, D. C.: Predicting global atmospheric ice nuclei distributions and their impacts on climate, P. Natl. Acad. Sci. USA, 107, 1121711222, doi:10.1073/pnas.0910818107, 2010.

Denman, K. L., Brasseur, G., Chidthaisong, A., Ciais, P., Cox, P. M., Dickinson, R. E., Hauglustaine, D., Heinze, C., Holland, E., 
Jacob, D., Lohmann, U., Ramachandran, S., Dias, P. L. d. S., Wofsy, S. C., and Zhang, X.: Couplings Between Changes in the Climate System and Biogeochemistry, in: Climate Change 2007: The Physical Science Basis. Contribution of Working Group I to the Fourth Assessment Report of the Intergovernmental Panel on Climate Change, edited by: Solomon, S., Qin, D., Manning, M., Chen, Z., Marquis, M., Averyt, K. B., Tignor, M., and Miller, H. L., Cambridge University Press, Cambridge, United Kingdom and New York, NY, USA, 2007.

Dentener, F. J., Carmichael, G. R., Zhang, Y., Lelieveld, J., and Crutzen, P. J.: Role of mineral aerosol as a reactive surface in the global troposphere, J. Geophys. Res.-Atmos., 101, 2286922889, 1996.

de Reus, M., Dentener, F., Thomas, A., Borrmann, S., Strom, J., and Lelieveld, J.: Airborne observations of dust aerosol over the North Atlantic Ocean during ACE 2: Indications for heterogeneous ozone destruction, J. Geophys. Res.-Atmos., 105, 1526315275, doi:10.1029/2000jd900164, 2000.

Diehl, K. and Wurzler, S.: Heterogeneous drop freezing in the immersion mode: Model calculations considering soluble and insoluble particles in the drops, J. Atmos. Sci., 61, 2063-2072, doi:10.1175/1520-0469(2004)061<2063:hdfiti>2.0.co;2, 2004.

Earle, M. E., Kuhn, T., Khalizov, A. F., and Sloan, J. J.: Volume nucleation rates for homogeneous freezing in supercooled water microdroplets: results from a combined experimental and modelling approach, Atmos. Chem. Phys., 10, 7945-7961, doi:10.5194/acp-10-7945-2010, 2010.

Eastwood, M. L., Cremel, S., Wheeler, M., Murray, B. J., Girard, E., and Bertram, A. K.: Effects of sulfuric acid and ammonium sulfate coatings on the ice nucleation properties of kaolinite particles, Geophys. Res. Lett., 36, L02811, doi:10.1029/2008g1035997, 2009.

Eidhammer, T., DeMott, P. J., and Kreidenweis, S. M.: A comparison of heterogeneous ice nucleation parameterizations using a parcel model framework, J. Geophys. Res.-Atmos., 114, D06202, doi:10.1029/2008jd011095, 2009.

Ervens, B. and Feingold, G.: Sensitivities of immersion freezing: Reconciling classical nucleation theory and deterministic expressions, Geophys. Res. Lett., 40, 3320-3324, doi:10.1002/grl.50580, 2013.

Field, P. R., Heymsfield, A. J., Shipway, B. J., DeMott, P. J., Pratt, K. A., Rogers, D. C., Stith, J., and Prather, K. A.: Ice in Clouds Experiment-Layer Clouds. Part II: Testing Characteristics of Heterogeneous Ice Formation in Lee Wave Clouds, J. Atmos. Sci., 69, 1066-1079, doi:10.1175/jas-d-11-026.1, 2012.

Hanisch, F. and Crowley, J. N.: Ozone decomposition on Saharan dust: an experimental investigation, Atmos. Chem. Phys., 3, 119130, doi:10.5194/acp-3-119-2003, 2003.

Hoose, C. and Möhler, O.: Heterogeneous ice nucleation on atmospheric aerosols: a review of results from laboratory experiments, Atmos. Chem. Phys., 12, 9817-9854, doi:10.5194/acp-12-98172012, 2012.

Hung, H. M., Malinowski, A., and Martin, S. T.: Kinetics of heterogeneous ice nucleation on the surfaces of mineral dust cores inserted into aqueous ammonium sulfate particles, J. Phys. Chem. A, 107, 1296-1306, 2003.

Jennings, S. G.: The mean free-path in air, J. Aerosol. Sci., 19, 159166, doi:10.1016/0021-8502(88)90219-4, 1988.
Kanji, Z. A. and Abbatt, J. P. D.: Laboratory studies of ice formation via deposition mode nucleation onto mineral dust and n-hexane soot samples, J. Geophys. Res.-Atmos., 111, D16204, doi:10.1029/2005JD006766, 2006.

Kanji, Z. A. and Abbatt, J. P. D.: Ice Nucleation onto Arizona Test Dust at Cirrus Temperatures: Effect of Temperature and Aerosol Size on Onset Relative Humidity, J. Phys. Chem. A, 114, 935941, doi:10.1021/jp908661m, 2010.

Kanji, Z. A., Florea, O., and Abbatt, J. P. D.: Ice formation via deposition nucleation on mineral dust and organics: dependence of onset relative humidity on total particulate surface area, Environ. Res. Lett, 3, 025004, doi:10.1088/1748-9326/3/2/025004, 2008.

Kanji, Z. A., DeMott, P. J., Möhler, O., and Abbatt, J. P. D.: Results from the University of Toronto continuous flow diffusion chamber at ICIS 2007: instrument intercomparison and ice onsets for different aerosol types, Atmos. Chem. Phys., 11, 31-41, doi:10.5194/acp-11-31-2011, 2011.

Karagulian, F. and Rossi, M. J.: The heterogeneous decomposition of ozone on atmospheric mineral dust surrogates at ambient temperature, Int. J. Chem. Kinet., 38, 407-419, doi:10.1002/kin.20175, 2006.

Knopf, D. A. and Alpert, P. A.: A Water Activity Based Model of Heterogeneous Ice Nucleation Kinetics for Freezing of Water and Aqueous Solution Droplets, Faraday Discuss., doi:10.1039/c3fd00035d, in press, 2013.

Knopf, D. A. and Koop, T.: Heterogeneous nucleation of ice on surrogates of mineral dust, J. Geophys. Res.-Atmos., 111, D12201, doi:10.1029/2005jd006894, 2006.

Knopf, D. A., Wang, B., Laskin, A., Moffet, R. C., and Gilles, M. K.: Heterogeneous nucleation of ice on anthropogenic organic particles collected in Mexico City, Geophys. Res. Lett., 37, L11803, doi:10.1029/2010g1043362, 2010.

Knopf, D. A., Alpert, P. A., Wang, B., and Aller, J. Y.: Stimulation of ice nucleation by marine diatoms, Nat. Geosci., 4, 88-90, doi:10.1038/ngeo1037, 2011.

Koehler, K. A., Kreidenweis, S. M., DeMott, P. J., Prenni, A. J., and Petters, M. D.: Potential impact of Owens (dry) Lake dust on warm and cold cloud formation, J. Geophys. Res.-Atmos., 112, D12210, doi:10.1029/2007JD008413, 2007.

Koehler, K. A., Kreidenweis, S. M., DeMott, P. J., Petters, M. D., Prenni, A. J., and Carrico, C. M.: Hygroscopicity and cloud droplet activation of mineral dust aerosol, Geophys. Res. Lett., 36, L08805, doi:10.1029/2009g1037348, 2009.

Kolb, C. E., Cox, R. A., Abbatt, J. P. D., Ammann, M., Davis, E. J., Donaldson, D. J., Garrett, B. C., George, C., Griffiths, P. T., Hanson, D. R., Kulmala, M., McFiggans, G., Pöschl, U., Riipinen, I., Rossi, M. J., Rudich, Y., Wagner, P. E., Winkler, P. M., Worsnop, D. R., and O' Dowd, C. D.: An overview of current issues in the uptake of atmospheric trace gases by aerosols and clouds, Atmos. Chem. Phys., 10, 10561-10605, doi:10.5194/acp-10-10561-2010, 2010.

Koop, T., Luo, B. P., Tsias, A., and Peter, T.: Water activity as the determinant for homogeneous ice nucleation in aqueous solutions, Nature, 406, 611-614, 2000.

Ladino, L., Stetzer, O., Luond, F., Welti, A., and Lohmann, U.: Contact freezing experiments of kaolinite particles with cloud droplets, J. Geophys. Res.-Atmos., 116, D22202, doi:10.1029/2011jd015727, 2011. 
Li, W. and Oyama, S. T.: Mechanism of ozone decomposition on a manganese oxide catalyst. 2. Steady-state and transient kinetic studies, J. Am. Chem. Soc., 120, 9047-9052, doi:10.1021/ja9814422, 1998.

Li, W. J. and Shao, L. Y.: Observation of nitrate coatings on atmospheric mineral dust particles, Atmos. Chem. Phys., 9, 1863 1871, doi:10.5194/acp-9-1863-2009, 2009.

Li, W., Gibbs, G. V., and Oyama, S. T.: Mechanism of ozone decomposition on a manganese oxide catalyst. I. In situ Raman spectroscopy and ab initio molecular orbital calculations, J. Am. Chem. Soc., 120, 9041-9046, doi:10.1021/ja981441+, 1998.

Lindzen, R. S.: Some Coolness Concerning Global Warming, B. Am. Meteorol. Soc., 71, 288-299, 1990.

Lohmann, U. and Feichter, J.: Global indirect aerosol effects: a review, Atmos. Chem. Phys., 5, 715-737, doi:10.5194/acp-5-7152005, 2005.

Lüönd, F., Stetzer, O., Welti, A., and Lohmann, U.: Experimental study on the ice nucleation ability of size-selected kaolinite particles in the immersion mode, J. Geophys. Res.-Atmos., 115, D14201, doi:10.1029/2009jd012959, 2010.

Marcolli, C., Gedamke, S., Peter, T., and Zobrist, B.: Efficiency of immersion mode ice nucleation on surrogates of mineral dust, Atmos. Chem. Phys., 7, 5081-5091, doi:10.5194/acp-7-50812007, 2007.

Michel, A. E., Usher, C. R., and Grassian, V. H.: Heterogeneous and catalytic uptake of ozone on mineral oxides and dusts: A Knudsen cell investigation, Geophys. Res. Lett., 29, 1665, doi:10.1029/2002g1014896, 2002.

Michel, A. E., Usher, C. R., and Grassian, V. H.: Reactive uptake of ozone on mineral oxides and mineral dusts, Atmos. Environ., 37, 3201-3211, doi:10.1016/s1352-2310(03)00319-4, 2003.

Mogili, P. K., Kleiber, P. D., Young, M. A., and Grassian, V. H.: Heterogeneous uptake of ozone on reactive components of mineral dust aerosol: An environmental aerosol reaction chamber study, J. Phys. Chem. A, 110, 13799-13807, doi:10.1021/jp063620g, 2006.

Möhler, O., DeMott, P. J., Vali, G., and Levin, Z.: Microbiology and atmospheric processes: the role of biological particles in cloud physics, Biogeosciences, 4, 1059-1071, doi:10.5194/bg-4-10592007, 2007.

Möhler, O., Benz, S., Saathoff, H., Schnaiter, M., Wagner, R., Schneider, J., Walter, S., Ebert, V., and Wagner, S.: The effect of organic coating on the heterogeneous ice nucleation efficiency of mineral dust aerosols, Environ. Res. Lett, 3, 025007, doi:10.1088/1748-9326/3/2/025007, 2008.

Murray, B. J., Broadley, S. L., Wilson, T. W., Atkinson, J. D., and Wills, R. H.: Heterogeneous freezing of water droplets containing kaolinite particles, Atmos. Chem. Phys., 11, 4191-4207, doi:10.5194/acp-11-4191-2011, 2011.

Murray, B. J., O'Sullivan, D., Atkinson, J. D., and Webb, M. E.: Ice nucleation by particles immersed in supercooled cloud droplets, Chem. Soc. Rev., 41, 6519-6554, doi:10.1039/c2cs35200a, 2012.

Nicolet, M., Stetzer, O., Lüönd, F., Möhler, O., and Lohmann, U.: Single ice crystal measurements during nucleation experiments with the depolarization detector IODE, Atmos. Chem. Phys., 10, 313-325, doi:10.5194/acp-10-313-2010, 2010.

Niedermeier, D., Hartmann, S., Shaw, R. A., Covert, D., Mentel, T. F., Schneider, J., Poulain, L., Reitz, P., Spindler, C., Clauss,
T., Kiselev, A., Hallbauer, E., Wex, H., Mildenberger, K., and Stratmann, F.: Heterogeneous freezing of droplets with immersed mineral dust particles - measurements and parameterization, Atmos. Chem. Phys., 10, 3601-3614, doi:10.5194/acp-10-36012010, 2010.

Niedermeier, D., Hartmann, S., Clauss, T., Wex, H., Kiselev, A., Sullivan, R. C., DeMott, P. J., Petters, M. D., Reitz, P., Schneider, J., Mikhailov, E., Sierau, B., Stetzer, O., Reimann, B., Bundke, U., Shaw, R. A., Buchholz, A., Mentel, T. F., and Stratmann, F.: Corrigendum to "Experimental study of the role of physicochemical surface processing on the IN ability of mineral dust particles" published in Atmos. Chem. Phys., 11, 11131-11144, 2011, Atmos. Chem. Phys., 11, 11919-11919, doi:10.5194/acp11-11919-2011, 2011a.

Niedermeier, D., Hartmann, S., Clauss, T., Wex, H., Kiselev, A., Sullivan, R. C., DeMott, P. J., Petters, M. D., Reitz, P., Schneider, J., Mikhailov, E., Sierau, B., Stetzer, O., Reimann, B., Bundke, U., Shaw, R. A., Buchholz, A., Mentel, T. F., and Stratmann, F.: Experimental study of the role of physicochemical surface processing on the IN ability of mineral dust particles, Atmos. Chem. Phys., 11, 11131-11144, doi:10.5194/acp11-11131-2011, 2011b.

Niemand, M., Mohler, O., Vogel, B., Vogel, H., Hoose, C., Connolly, P., Klein, H., Bingemer, H., DeMott, P., Skrotzki, J., and Leisner, T.: A Particle-Surface-Area-Based Parameterization of Immersion Freezing on Desert Dust Particles, J. Atmos. Sci., 69, 3077-3092, doi:10.1175/jas-d-11-0249.1, 2012.

Pinti, V., Marcolli, C., Zobrist, B., Hoyle, C. R., and Peter, T.: Ice nucleation efficiency of clay minerals in the immersion mode, Atmos. Chem. Phys., 12, 5859-5878, doi:10.5194/acp-12-58592012, 2012.

Pratt, K. A., DeMott, P. J., French, J. R., Wang, Z., Westphal, D. L., Heymsfield, A. J., Twohy, C. H., Prenni, A. J., and Prather, K. A.: In situ detection of biological particles in cloud ice-crystals, Nat. Geosci., 2, 397-400, doi:10.1038/ngeo521, 2009.

Prospero, J. M.: Long-range transport of mineral dust in the global atmosphere: Impact of African dust on the environment of the southeastern United States, P. Natl. Acad. Sci. USA, 96, 33963403, 1999.

Pruppacher, H. R. and Klett, J. D.: Microphysics of Clouds and Precipitation, 2nd Edn., Kluwer, Dordrecht, 976 pp., 1997.

Richardson, M. S., DeMott, P. J., Kreidenweis, S. M., Cziczo, D. J., Dunlea, E. J., Jimenez, J. L., Thomson, D. S., Ashbaugh, L. L., Borys, R. D., Westphal, D. L., Casuccio, G. S., and Lersch, T. L.: Measurements of heterogeneous ice nuclei in the western United States in springtime and their relation to aerosol characteristics, J. Geophys. Res.-Atmos., 112, D02209, doi:10.1029/2006jd007500, 2007.

Rigg, Y. J., Alpert, P. A., and Knopf, D. A.: Immersion freezing of water and aqueous ammonium sulfate droplets initiated by humic-like substances as a function of water activity, Atmos Chem. Phys., 13, 6603-6622, doi:10.5194/acp-13-6603-2013, 2013.

Rogers, D. C.: Development of a continuous flow thermal gradient diffusion chamber for ice nucleation studies, Atmos. Res., 22, 149-181, doi:10.1016/0169-8095(88)90005-1, 1988.

Roscoe, J. M. and Abbatt, J. P. D.: Diffuse reflectance FTIR study of the interaction of alumina surfaces with ozone and water vapor, J. Phys. Chem. A, 109, 9028-9034, doi:10.1021/jp050766r, 2005. 
Salam, A., Lohmann, U., Crenna, B., Lesins, G., Klages, P., Rogers, D., Irani, R., MacGillivray, A., and Coffin, M.: Ice nucleation studies of mineral dust particles with a new continuous flow diffusion chamber, Aerosol Sci. Technol., 40, 134-143, doi:10.1080/02786820500444853, 2006.

Salam, A., Lesins, G., and Lohmann, U.: Laboratory study of heterogeneous ice nucleation in deposition mode of montmorillonite mineral dust particles aged with ammonia, sulfur dioxide, and ozone at polluted atmospheric concentrations, Air Qual. Atmos. Health, 1, 135-142, doi:10.1007/s11869-008-0019-6, 2008.

Sassen, K., DeMott, P. J., Prospero, J. M., and Poellot, M. R.: Saharan dust storms and indirect aerosol effects on clouds: CRYSTAL-FACE results, Geophys. Res. Lett., 30, 1633, doi:10.1029/2003GL017371, 2003.

Satheesh, S. K. and Moorthy, K. K.: Radiative effects of natural aerosols: A review, Atmos. Environ., 39, 2089-2110, doi:10.1016/j.atmosenv.2004.12.029, 2005.

Spichtinger, P. and Cziczo, D. J.: Impact of heterogeneous ice nuclei on homogeneous freezing events in cirrus clouds, J. Geophys. Res.-Atmos., 115, D14208, doi:10.1029/2009jd012168, 2010.

Stetzer, O., Baschek, B., Luond, F., and Lohmann, U.: The Zurich Ice Nucleation Chamber (ZINC) - A new instrument to investigate atmospheric ice formation, Aerosol Sci. Technol., 42, 6474, doi:10.1080/02786820701787944, 2008.

Streets, D. G., Fu, J. S., Jang, C. J., Hao, J., He, K., Tang, X., Zhang, Y., Wang, Z., Li, Z., Zhang, Q., Wang, L., Wang, B., and Yu, C.: Air quality during the 2008 Beijing Olympic Games, Atmos. Environ., 41, 480-492, doi:10.1016/j.atmosenv.2006.08.046, 2007.

Sullivan, R. C. and Prather, K. A.: Investigations of the diurnal cycle and mixing state of oxalic acid in individual particles in Asian aerosol outflow, Environ. Sci. Technol., 41, 8062-8069, doi:10.1021/es071134g, 2007.

Sullivan, R. C., Thornberry, T., and Abbatt, J. P. D.: Ozone decomposition kinetics on alumina: effects of ozone partial pressure, relative humidity and repeated oxidation cycles, Atmos. Chem. Phys., 4, 1301-1310, doi:10.5194/acp-4-1301-2004, 2004.

Sullivan, R. C., Guazzotti, S. A., Sodeman, D. A., and Prather, K. A.: Direct observations of the atmospheric processing of Asian mineral dust, Atmos. Chem. Phys., 7, 1213-1236, doi:10.5194/acp-7-1213-2007, 2007a.

Sullivan, R. C., Guazzotti, S. A., Sodeman, D. A., Tang, Y. H., Carmichael, G. R., and Prather, K. A.: Mineral dust is a sink for chlorine in the marine boundary layer, Atmos. Environ., 41, 7166-7179, doi:10.1016/j.atmosenv.2007.05.047, 2007b.

Sullivan, R. C., Minambres, L., DeMott, P. J., Prenni, A. J., Carrico, C. M., Levin, E. J. T., and Kreidenweis, S. M.: Chemical processing does not always impair heterogeneous ice nucleation of mineral dust particles, Geophys. Res. Lett., 37, L24805, doi:10.1029/2010g1045540, 2010a.

Sullivan, R. C., Petters, M. D., DeMott, P. J., Kreidenweis, S. M., Wex, H., Niedermeier, D., Hartmann, S., Clauss, T., Stratmann, F., Reitz, P., Schneider, J., and Sierau, B.: Irreversible loss of ice nucleation active sites in mineral dust particles caused by sulphuric acid condensation, Atmos. Chem. Phys., 10, 1147111487, doi:10.5194/acp-10-11471-2010, 2010b.

Twohy, C. H. and Poellot, M. R.: Chemical characteristics of ice residual nuclei in anvil cirrus clouds: evidence for homogeneous and heterogeneous ice formation, Atmos. Chem. Phys., 5, 2289 2297, doi:10.5194/acp-5-2289-2005, 2005.
Usher, C. R., Michel, A. E., and Grassian, V. H.: Reactions on mineral dust, Chem. Rev., 103, 4883-4939, doi:10.1021/cr020657y, 2003a.

Usher, C. R., Michel, A. E., Stec, D., and Grassian, V. H.: Laboratory studies of ozone uptake on processed mineral dust, Atmos. Environ., 37, 5337-5347, 2003 b.

Vali, G.: Nucleation terminology, B. Am. Meteorol. Soc., 66, 14261427, 1985.

Vlasenko, A., Sjogren, S., Weingartner, E., Gaggeler, H. W., and Ammann, M.: Generation of submicron Arizona test dust aerosol: Chemical and hygroscopic properties, Aerosol Sci. Technol., 39, 452-460, doi:10.1080/027868290959870, 2005.

Wagner, C., Hanisch, F., Holmes, N., de Coninck, H., Schuster, G. and Crowley, J. N.: The interaction of $\mathrm{N}_{2} \mathrm{O}_{5}$ with mineral dust: aerosol flow tube and Knudsen reactor studies, Atmos. Chem. Phys., 8, 91-109, doi:10.5194/acp-8-91-2008, 2008.

Wang, B. B. and Knopf, D. A.: Heterogeneous ice nucleation on particles composed of humic-like substances impacted by O-3, J. Geophys. Res.-Atmos., 116, D03205, doi:10.1029/2010jd014964, 2011.

Wang, B. B., Laskin, A., Roedel, T., Gilles, M. K., Moffet, R. C., Tivanski, A. V., and Knopf, D. A.: Heterogeneous ice nucleation and water uptake by field-collected atmospheric particles below 273 K, J. Geophys. Res.-Atmos., 117, D00v19, doi:10.1029/2012jd017446, 2012.

Welti, A., Lüönd, F., Stetzer, O., and Lohmann, U.: Influence of particle size on the ice nucleating ability of mineral dusts, Atmos. Chem. Phys., 9, 6705-6715, doi:10.5194/acp-9-6705-2009, 2009.

Welti, A., Lüönd, F., Kanji, Z. A., Stetzer, O., and Lohmann, U.: Time dependence of immersion freezing: an experimental study on size selected kaolinite particles, Atmos. Chem. Phys., 12, 9893-9907, doi:10.5194/acp-12-9893-2012, 2012.

Westbrook, C. D. and Illingworth, A. J.: The formation of ice in a long-lived supercooled layer cloud, Q. J. Roy. Meteor. Soc., doi:10.1002/qj.2096, in press, 2013.

Wheeler, M. J. and Bertram, A. K.: Deposition nucleation on mineral dust particles: a case against classical nucleation theory with the assumption of a single contact angle, Atmos. Chem. Phys., 12, 1189-1201, doi:10.5194/acp-12-1189-2012, 2012.

Yin, X. and Miller, J. D.: Wettability of kaolinite basal planes based on surface force measurements using atomic force microscopy, Miner. Metall. Proc., 29, 13-19, 2012.

Zettlemoyer, A. C., Tcheurekdjian, N., and Chessick, J. J.: Surface Properties of Silver Iodide, Nature, 192, 653-653, 1961.

Zimmermann, F., Ebert, M., Worringen, A., Schutz, L., and Weinbruch, S.: Environmental scanning electron microscopy (ESEM) as a new technique to determine the ice nucleation capability of individual atmospheric aerosol particles, Atmos. Environ., 41, 8219-8227, doi:10.1016/j.atmosenv.2007.06.023, 2007.

Zipser, E. J., Twohy, C. H., Tsay, S.-C., Hsu, N. C., Heymsfield, G. M., Thornhill, K. L., Tanelli, S., Ross, R., Krishnamurti, T. N., Ji, Q., Jenkins, G., Ismail, S., Ferrare, R., Chen, G., Browell, E. V., Anderson, B., Hood, R., Goodman, H. M., Heymsfield, A., Halverson, J., Dunion, J. P., Douglas, M., and Cifelli, R.: The Saharan Air Layer and the Fate of African Easterly Waves NASA's AMMA Field Study of Tropical Cyclogenesis, B. Am. Meteorol. Soc., 90, 1137-1156, doi:10.1175/2009bams2728.1, 2009. 